\title{
Physical Activity and Natural Products and Minerals in the SARS-CoV-2 Pandemic: An Update
}

\author{
${ }^{1}$ Ayoub Saeidi, ${ }^{2}$ Seyed Morteza Tayebi, ${ }^{3}$ Oam To-aj*, ${ }^{4}$ Niloofar Karimi, ${ }^{5}$ Sahar \\ Kamankesh, ${ }^{6}$ Saber Niazi, ${ }^{7}$ Abedin Khosravi, ${ }^{8}$ Mitra Khademosharie, ${ }^{9}$ Mohammad \\ Soltani, ${ }^{10}$ Kelly E. Johnson, ${ }^{11}$ Harunor Rashid, ${ }^{12}$ Ismail Laher, ${ }^{13}$ Anthony C. Hackney, \\ ${ }^{14}$ Hassane Zouhal* \\ ${ }^{1}$ Damghan Branch, Islamic Azad University, Damghan, Iran. ${ }^{2}$ Allameh Tabataba'i University, Tehran, \\ Iran. ${ }^{3}$ Bangkok Thonburi University, Bangkok, Thailand. ${ }^{4}$ University of Mazandaran, Babolsar, Iran. ${ }^{5}$ Razi \\ University, Kermanshah, Iran. ${ }^{6}$ Kharazmi University, Tehran, Iran. ${ }^{7}$ Payame Noor University, Tehran, \\ Iran. ${ }^{8}$ Kowsar University, Bojnord, Iran. ${ }^{9}$ Shahid Beheshti University, Tehran, Iran. ${ }^{10}$ Coastal Carolina \\ University, Conway SC, USA. ${ }^{11}$ National Centre for Immunisation Research \& Surveillance of Vaccine \\ Preventable Diseases (NCIRS), Westmead, Australia. ${ }^{12}$ University of British Columbia, Vancouver, \\ Canada. ${ }^{13}$ University of North Carolina, Chapel Hill, NC, USA. ${ }^{14}$ University of Rennes 2, Rennes, France.
}

Submitted 10 January 2021; Accepted in final form 14 February 2021.

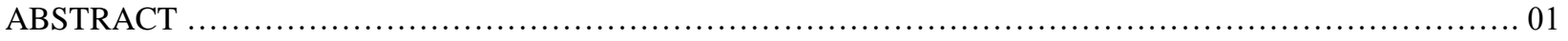

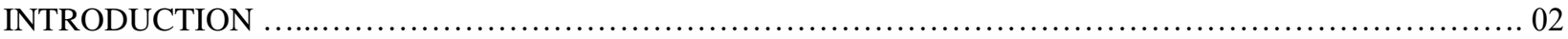

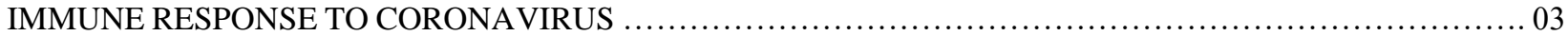

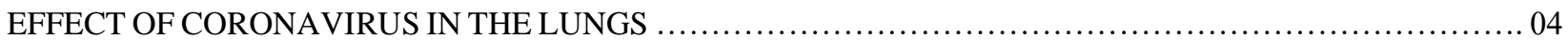

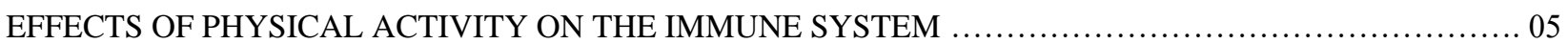

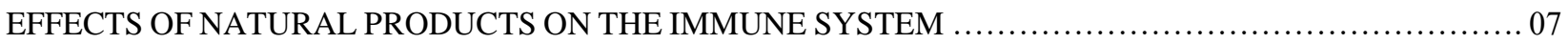

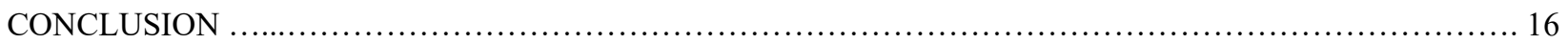

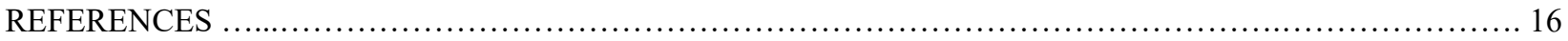

\begin{abstract}
Coronavirus-disease 19 (COVID-19) has rapidly become a global public health issue, and there is a desperate need for strategies of prevention, reduction, and treatment to halt the epidemic. The coronavirus affects the immune system, and individuals with a compromised immune system, such as those with diabetes, hypertension, obesity, are more susceptible to this virus. Lifestyle-related variables such as physical activity and nutritional supplements can decrease inflammatory markers, increase anti-inflammatory and antioxidant status, and improve the immune system. Lifestylerelated variables play preventive roles against various infectious diseases including COVID-19. This review highlights the effects of physical activity and nutrients supplements on the immune system and their possible benefits in combating the harms caused by infection with the COVID-19 virus.

KEYWORDS: Coronavirus, Covid-19, Immune Response, Immune System, Lung Tissue, Inflammation, AntiInflammatory, Cellular Effects, Hormonal Effects, Antioxidant, Nutrition, Nutrients Supplements, Curcumin, Black Cumin, Adiantum Capillus-Veneris, Thyme, Ginger, Cinnamon, Zinc, Vitamin C, Garlic, Beeswax, Honey, Selenium, Lemon, Magnesium, Physical Activity, Sport, Exercise, Training.
\end{abstract}

*. Corresponding Authors:

1. Oam To-aj, PhD. E-Mail: Oam.deto@gmail.com

2. Hassane Zouhal, Professor. E-Mail: hassane.zouhal@univ-rennes2.fr 


\section{INTRODUCTION}

The word coronavirus is derived from the Greek word "korone", meaning something curved, and the Latin word "corona", meaning garland or crown. The term refers to the appearance of virions (the infectious form of the virus) seen under an electron microscope, which has a large, onion-like margin and is reminiscent of a picture of a royal crown or solar crown, so that the coronavirus is sometimes also referred to as the crown virus (1). Different coronaviruses have been identified in dogs, rabbits, mice, chickens, turkeys, cows, cats, horses, and humans, and can cause a variety of serious illnesses including gastrointestinal and respiratory diseases (1). A series of symptoms of pneumonia with clinical signs very similar to viral pneumonia appeared in Wuhan (China) in December 2019, which soon spread worldwide including several cases of pneumonia of unknown etiology $(2,3)$. In the early stages of the disease, severe acute symptoms of respiratory infection occurred, with some patients rapidly developing acute respiratory distress syndrome (ARDS) (4). A new coronavirus was then identified by the Chinese Center for Disease Control and Prevention (CDC) from a swab of a patient's throat, and subsequently named by the WHO as the 2019-nCOV, COVID-19 (4). The disease then quickly spread to 27 other countries (5).

Coronaviruses (CoVs) are single, nonfragmented, enveloped single-stranded viral genomes ranging in size from 26 to 32 kilobases, and represent the largest known RNA virus genome (6). Virion has a nucleocapsid composed of genomic RNA protein and phosphorylated nucleoprotein $(\mathrm{N})$ protein, which is located within the phospholipid layers and is covered by two different types of spike proteins (6). Spike glycoprotein $(\mathrm{S})$ is found in all $\mathrm{CoVs}$, while hemagglutinin esterase (HE) is found only in some CoVs (6). Membrane protein (M) (a type III transmembrane glycoprotein) and envelope (E) proteins are among the $\mathrm{S}$ proteins in the virus envelope (6). The subfamily Coronavirus is genetically and serologically divided into four genera: $\alpha, \beta, \gamma$, and $\delta$. Coronavirus $\beta$ - can be further classified into four virus classes, A-D (6). There are about 30 kinds of CoVs that infect humans, mammals, chickens and other animals (6). Human CoV infection is caused by corona viruses $\alpha$ and $\beta$ (6).
Seven coronaviruses transmitted from animals to humans have been identified by their host range and genome sequence (7). Among them, $\mathrm{HCoV}$ 229E and HCoV-OC43 were identified in the mid-1960s as causing common colds (7). Other corona viruses are $\mathrm{HCoV}-\mathrm{NL} 63$ and $\mathrm{HCoV}-$ HKU1, which were discovered in 2004 and 2005 (7). Severe acute respiratory syndrome coronavirus (SARS-CoV) killed about 800 people in 2002-2003, causing acute and severe respiratory distress syndrome $(1,8)$. A newer strain of the virus, Middle East Respiratory Syndrome coronavirus (MERS-CoV) was first discovered in 2012 in a 60-year-old man in Saudi Arabia (9) and a second case in a 49-year-old man in Qatar (9); both cases were fatal (10). Another new corona causing Severe Acute Respiratory Syndrome (SARS-CoV-2) was later identified in 2019 (2). Similar to SARS-CoV and MERS-CoV, the 2019-nCoV encodes non-structural proteins (such as quimotrypsin-3-like protease, quaternary papain, helicase and RNA dependent RNA polymerase), structural proteins (such as spike glycoprotein) and side protein $(6,11)$. These four non-structural proteins are key enzymes in the virus life cycle, and the spike glycoprotein is essential for cell-virus receptor interactions for viral invasion (11).

Preliminary analyzes of SARS-CoV-2 genomic sequences indicates that the catalytic sites are protected from the four SARS-CoV-2 enzymes that can be antiviral targets, and have a high level of sequence similarity to SARS-CoV and MERS-CoV enzymes (12). In addition, structural analysis of the protein suggests that important pockets of drug binding in virus enzymes are probably similar in all corona viruses such as COVID-19, SARS and MERS-CoV (12). The $2019-\mathrm{nCoV}$ virus has a $96 \%$ similarity with the bat coronavirus, making the bat a widely suspected source of transmission, but the origin of the 2019-nCoV still needs further investigation (13). Common symptoms of infection with the Covid-19 virus include fever and cough. Muscle pain, sputum production, and sore throat are less common, and in most cases lead to milder symptoms severe cases may present with shortness of breath. People infected with the virus can be asymptomatic or present with flu-like symptoms (14). Diarrhea and upper respiratory symptoms such as sneezing, runny nose or sore throat are less common $(14,15)$. Viral 
transmission can occur through respiratory droplets as often occurs during coughing and sneezing or direct or indirect contact $(15,16)$. According to the World Health Organization, the duration of symptoms is usually between 2 and 14 days, with an average of 5 days (16). Preliminary data suggests that transition of the disease to severe illness is within 1 week (16), with the onset of symptoms being 2-8 weeks in fatal cases (16). The standard method of diagnosis is through reverse polymerase chain reaction (RT-PCR) of a throat swab. Infection also can be detected by a combination of symptoms, risk factors, and CT scans of the chest that show the characteristics of pneumonia (14). Mortality is estimated as between 1 and 5 percent in infected people but can vary according to age and other health conditions (14). There are a larger number of males in a study of 99 cases of 2019-nCoV infections (14)(14), similar to findings in of infections with As MERS-CoV and SARS-CoV (14). Reduced susceptibility of women to viral infections can be attributed to protection against the $\mathrm{X}$ chromosome and sex hormones, which play an important role in innate immunity (17). About half of the patients infected with 2019-nCoV were reported to have serious complications related to cardiovascular, brain and diabetes, and 2019$\mathrm{nCoV}$ due to poor immune function. It is more likely to infect older men (14).

The immune system protects the body against bacteria and viruses that can harm the body and lead to illness and infections (18). There are several factors which affect the function of immune system: age, gender, diet, pre-existing medical illness and physical activity (PA) level $(19,20)$. The global spread of COVID-19 means the need for people to protect themselves by maintaining their health, with PA and diet being two factors that can boost the immune system and provide protection against viral infections (19, 20). The clinical characteristics of people infected with the COVID-19 virus indicates increases in inflammatory cytokines ("cytokine storm") and decrease in anti-inflammatory markers through cellular changes may weaken the immune system and is leading to invade of this virus to the sensitive parts of the body, especially in the lungs (6). This review highlights the effects of PA and nutritional supplements on the immune system and their possible benefits in relieving the harms of viral infections for example, with the COVID19 virus.
IMMUNE RESPONSE TO CORONAVIRUS

A viral infection leads to an activation of the host immune system, and when immune defenses are overwhelmed, there is lung tissue damage and decreased lung capacity (21). Chemotactic agents are critical for immune responses to viral infections due to their regulatory effects on the spread and location of leukocytes in the pulmonary system (21). Accordingly, spectral changes in chemotactic factors may lead to highly maladaptive immune responses. Immune deficiency or a change in direction in the immune system can increase virus proliferation and cause tissue damage, while hyperactive immune responses can induce immune-related pathological conditions (21). The host's innate immune system detects viral infections using pattern recognition receptors (PRR) to detect pathogen-related molecular patterns (PAMPs) (21). PRRs mainly includes toll - like (TLR) receptors, RIG - I - like (RLR) receptors, NOD like receptors (NLR), and C-type pseudo-lectin receptors (CLmin), and also molecules in the cytoplasm such as cGAS, IFI16, STING, and DAI (21). On the other hand, adaptive immune systems ( $\mathrm{T}$ cells, CD4 $+\mathrm{T}$ cells and CD8 $+\mathrm{T}$ cells) plays a significant role against the virus (22).

Cytokine storm in Covid-19 infections. White blood CD4 cells, also known as T helper cells or simply as $\mathrm{T}$ cells, produce specific B-cells that produce virus-specific antibodies, while $\mathrm{CD} 8+\mathrm{T}$ cells are cytotoxic and can eradicate virusinfected cells (23). The CD8 $+\mathrm{T}$ comprise about $80 \%$ of the inflammatory cells that penetrate the lungs of COVID-19 patients, and have an important role in clearing CoVs in infected cells (23). The innate immune response and adaptive immune responses in $\mathrm{CoV}$ infection are such that the $\mathrm{CoV}$ then infect macrophages, which can subsequently provide the $\mathrm{CoV}$ antigen to $\mathrm{T}$ cells (6). This process activates and differentiates $\mathrm{T}$ cells, including the production of cytokines associated with various subtypes of $\mathrm{T}$ cells (i.e. Th17), followed by the widespread release of cytokines to enhance the immune response (6). Continued production of these mediators negatively affects the activation of natural killer (NK) and CD8+-T cells due to viral persistence (6). However, CD8+T cells produce mediators able to clear COVID-19 viral particles (6). On the other hand, the binding of CoV to DPP4R on the host cell via $S$ protein leads to the emergence of 
genomic RNA in the cytoplasm, allowing CoV replication to occur partially as a result of dsRNA (6). The stimulation of TLR-3 stimulated by dsRNA signals IRFs and NF- $\kappa B$ activation to produce IFNs and cytokines (6). Production of 1 type IFNs is important to increase the release of antivirus proteins to protect non-infectious cells (6). CoV side proteins can also interfere with TLR-3 signaling and add to the effects of dsRNA in increasing $\mathrm{CoV}$ proliferation, so preventing TLR-3 activation and preventing a robust immune response (6). TLR-4 can detect protein $\mathrm{S}$ and lead to the activation of pre-inflammatory cytokines via the MyD88-dependent signaling pathway, and increase the production of immune mediators (6). The secretion of large amounts of chemokines and cytokines (IL-1, IL-6, IL-8, IL-21, TNF- $\beta$, and MCP-1) in infected cells is enhanced in response to $\mathrm{CoV}$ infection (6). These chemokines and cytokines, in turn, adsorb lymphocytes and leukocytes at the site of infection (6).

\section{EFFECT OF CORONA VIRUS IN THE LUNGS}

Lung damage caused by a virus initiates an immune, tissue damage and an accumulation of waste products (24). The extent of viral damage is related to the phase gap between the virus's reproductive curve and the compromised immune response delay, while lesion-related damage is attributed to an imbalance in the destruction of virus, cellular, and metabolic products (24). Treatment strategies should be aimed to slow viral reproduction, accelerate the immune response, and improve circulation in the lungs (24). Accordingly, treatment strategies should neutralize direct lung infection, strengthen and promote immune responses, dilute the viral concentration in lung tissue, maintain the balance of waste products, protect the heart and kidneys, and control other infections (24). Allergic reactions and other inflammatory responses should be managed, and monitoring of diet, emotional factors, lifestyle, and environmental factors, will also help to reduce lung damage (24).

Lungs are damaged by the rapid increase in resistance due to the retention of white blood cells in the lung tissue. White blood cell retention initially causes a viral infection but is exacerbated by low-temperature injuries. The lungs are initially damaged by fluid leakage, which is accelerated by the rapid release of blood into the alveolar spaces.
Ii is estimated that a retention of white blood cells in the lungs by $0.1 \%$ can lead to failure in 5 to 10 days (25). Suggesting importance of maintaining the microcirculation and the function of body organs during the disease, especially after the spread of the virus in the lungs (25).

The lungs are affected the most by COVID-19 because the virus has access to host cells through the enzyme angiotensin-converting enzyme 2 (ACE2), which is abundant in alveolar type II lung cells $(5,26)$. Cleavage of surface specific glycoproteins (initially called spike proteins) by transmembrane protease serine 2 (TMPRSS2) allows the entry and spread of SARS-CoV-2 virus through interaction with ACE2 receptors, leading to severe lung damage $(27,28)$. Tissue damage is proportional to the density of ACE2, suggesting that decreased ACE2 activity may be protective, e.g by inhibiting TMPRSS2 $(27,28)$. TMPRSS2 promotes the spread of the virus in the airways of rat models after coronavirus infection (5). Alveolar disease leads to respiratory failure and death (29). ACE2 can also allow the COVID-19 virus to invade the heart and cause acute heart damage, further increasing the vulnerability of people with existing cardiovascular conditions (29).

The COVOD-19 virus particles spread through the respiratory mucosa, infecting other cells and activating cytokines in the body, altering peripheral white blood cells and immune cells such as lymphocytes (14). The absolute number of lymphocytes in most infected patients is decreased, suggesting that COVID-19s acts primarily on lymphocytes, especially $\mathrm{T}$ lymphocytes, much as is the case for SARS-CoV (14). Some patients rapidly develop acute respiratory distress syndrome (ARDS), and later develop to multiple organ failure (14). Intravenous administration of immunoglobulin and treatment with steroids (methylprednisolone $1-2 \mathrm{mg} / \mathrm{kg} /$ day) is recommended for highly infected patients who develop ARDS (14).

A first step in combating disease is to prevent exposure to the COVID-19 virus, and in the absence of effective treatment strategies, a second step is to use health optimization methods through changes in lifestyle such as exercise and improved nutrition (25).

\section{EFFECTS OF PHYSICAL ACTIVITY ON THE IMMUNE SYSTEM}

Some studies have investigated the effects of PA on the immune system, but with conflicting 
results (30-32). The response of the immune system to PA is related to the intensity, duration and the type of PA $(30,31,33-35)$. According to the results of epidemiological studies on the effects of PA on the function of the immune system, there is a J-shaped curve describing the relationship between exercise intensity and risk of infection, where moderate PA can enhance immune function, while high intensity PA can impair immune function while exhaustive exercise can be detrimental and increase the risk to infections $(33,36)$ (Fig 1).

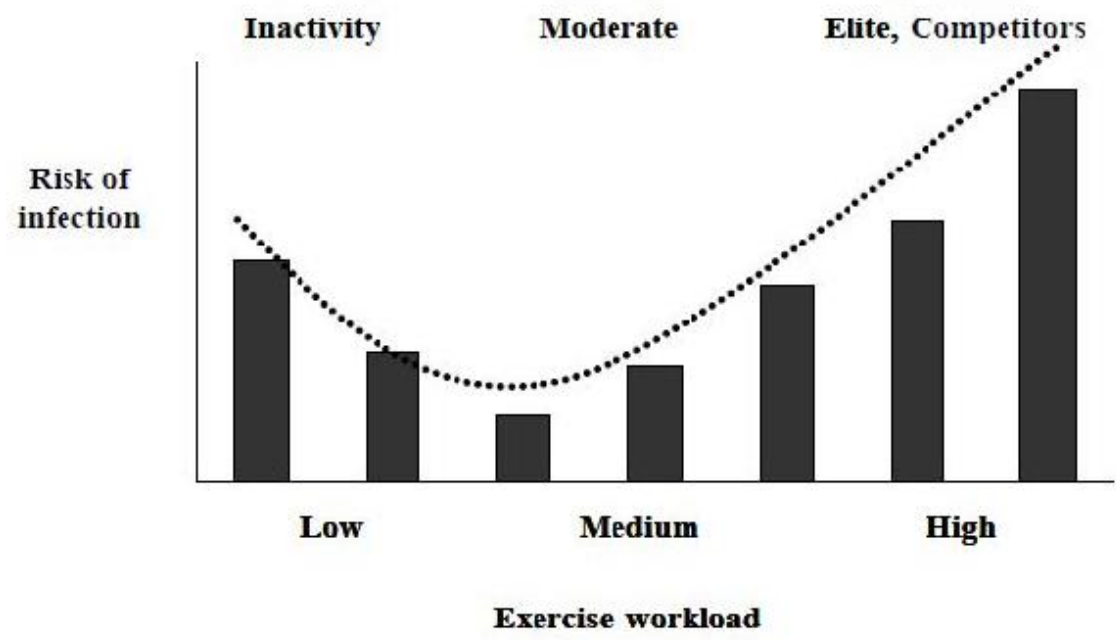

Figure 1. The risk of infection in relation to PA workload (33).

Appropriate levels and types of exercise increase anti-inflammatory $(31,32,36,37)$ and antioxidant biomarkers (37-40) and improves the immune defenses against viral infections (30, 33, $35,39,41)$. Psychological stress on the other hand is linked to inflammation and oxidative stress, both of which are associated with immune dysfunction (30, 42-44)

Anti-Inflammatory Effects of Physical Activity. Patients with a weakened immune system are likely to have a severe disease if infected with the SARS-CoV-2 with high levels of inflammatory biomarkers such as tumor necrosis factor (TNF), interleukin-6 (IL-6) and Creactive protein (CRP) $(18,45,46)$. The antiinflammatory effects of PA can be achieved through a reduction of visceral fat mass $(47,48)$, as indicated by increases in anti-inflammatory biomarkers $(31,32)$ and reduced expression of Toll-like receptors (TLRs) on monocytes and macrophages (49). Adipose tissue increases the production of pro-inflammatory adipokines and decreases anti-inflammatory cytokines such as IL-10 and IL-1 receptor antagonist (IL-1ra) (31, $50)$.

A study of 1293 middle-aged patients reported that cardiorespiratory fitness was inversely associated with CRP, IL-6, and IL-18, and directly associated with the anti-inflammatory cytokine IL-10; these effects are partly explained by a reduction in abdominal obesity and a decrease in the metabolic syndrome risk profile (48). Another study demonstrated that 8 weeks of combined aerobic and resistance training improved body composition (weight, body mass index (BMI), body fat\%), inflammatory (IL-6, $\mathrm{CRP}$ and TNF- $\alpha$ ) and immune markers (leukocyte, natural killer (NK) cells) in obese adult men (47). Moreover, changes in lifestyle such as diet and PA in obese women decreased leptin, CRP and IL-6 and increased interleukin levels, and accompanied by decreases in BMI, waist-to-hip ratio, and fasting insulin concentrations (51).

There is a short-term transient increase in serum CRP after strenuous PA, a response that is largely mediated by IL-6. Based on the open window theory, immune system during this period has a weakened ability to combat bacteria and viruses for a period lasting from a few hours up to a day $(33,52)$.

Other causes of inflammation and increases in inflammatory markers during PA are mechanical changes and dehydration in the airways, and environmental factors such as air pollution and allergens can exacerbate inflammation and 
further weaken the immune defenses $(33,53)$. Consuming fluids to reduce dehydration is one of the strategies to reduce the complications of COVID-19 (14).

Activation of TLR signaling increases the expression and secretion of pro-inflammatory cytokines; TLR mediates systemic inflammation and provides a link between a sedentary lifestyle, inflammation and disease. Regular PA downregulates TLR expression and reduces inflammatory responses and the risk of chronic inflammatory diseases $(31,49)$. As indicated in studies, after PA, appearance of IL-10 and IL-1ra in the circulation will be increased which contributes to mediating the anti-inflammatory effects of PA (54). IL-10 inhibits the production of cytokines and chemokines and plays an important role on the inflammatory reaction involving macrophage/monocyte activation (31, 54).

Cellular Effects of Physical Activity. A large number of immune cell infiltration occurs in patients with COVID-19. Most cellular responses to PA are related to changes in the total number and composition of circulatory leukocytes; these responses are different in the various stages before, during and a few hours after PA cessation (34). The dominant immune cell changes with PA are neutrophils and lymphocytes, with a smaller contribution of monocytes. The total leukocytes count during PA is related to the intensity and duration of the PA, the fitness level and age of the individual (39). A bout of intensive PA elevates blood neutrophil count and decreases natural killer cell (NK) activity, followed by a rapid reduction in lymphocytes $(30,34)$. Increases in circulating numbers of pro-inflammatory monocytes then occur in response to TLR (30, 34). Based on the open window theory, these transient changes may remain for several hours to days $(30,34)$, but is followed by thorough compensatory intracellular and extracellular changes $(30,31)$.

Increases in leukocytes by exercise can reduce immune burden (55). Raised levels of IL-6 due to excessive PA increases the secretion of adrenocorticotrophic hormone (ACTH), which stimulates cortisol release; cortisol has antiinflammatory effects $(54,55)$. Acute increases in IL-6 stimulates the release of IL-1 ra from monocytes and macrophages (54). Regular PA increases levels of circulating regulatory $\mathrm{T}$ cells (TReg cells) decreases inflammatory
(CD14lowCD16+) monocytes and the expression of TLR4 in macrophages, ultimately boosting immunity against viruses and infections (31).

A study in young mice reports that highintensity PA increases CD4+ CD25+ TReg cell numbers and decreases IFN- $\gamma$ expression and Tlymphocyte proliferation, changes that were associated with reduced pro-inflammatory markers and increased anti-inflammatory cytokine expression (35). In contrast, another study in elderly individuals demonstrated that 6 months of moderate PA improved expression of CD4+ on T-helper (Th) cells and the balance of Th1/Th2 and decreased the risk of infections and autoimmune diseases $(41)(35,41)$. On the other hand, a study by Wolach et al (2000) reported decreased function of neutrophils in female judo athletes compared to sedentary women after prolonged endurance PA, while cross-sectional studies show boosted NK cell activity in athletes compared with non-athletes in both younger and older groups (56). These findings indicate that the cellular responses to PA are largely related to the individuals' level of fitness, the intensity and duration of the PA, and also the age of the individual.

An organized PA and healthy nutritional status preserves the anti-inflammatory phenotype of adipose tissue by resizing adipocytes and increasing M2-type macrophages and CD4+ TReg cells (31). Acute and chronic PA produces anti-inflammatory cytokines such as IL-10 and IL-1ra by modulating the distribution of Th2 cells, Th1 cells, Th17 cells, monocytes, macrophages, dendritic cells (DCs), B cells, CD8+ T cells and CD4+ T cells $(31,35,39)$.

Several studies report that the effects of PA are related to changes in immunoglobulins (Ig), specifically $\operatorname{IgA}(30,31,57)$. $\operatorname{IgA}$ is activated by pathogens that invade the upper respiratory tract (57). A study by Klentrou et al (2002) reported that moderate PA increases resting salivary $\operatorname{IgA}$ concentrations in people with regular PA (58). PA modulates activity of the renin-angiotensin system (RAS), with some experimental studies reporting that PA can stimulate the ACE2-Ang(1-7)-Mas receptor axis in parallel with the inhibition of the ACE-Ang II-AT1 receptor pathway (59). A study by Magalhães et al (2020) indicates that both moderate and high-intensity aerobic PA increases ACE2 levels, but with greater increases after moderate-intensity aerobic PA (60). Another study by Prata et al (2017) 
showed for the first time that exercise training activation of ACE2 can potentially reduce pulmonary fibrosis (61).

Hormonal Effects of Physical Activity. PA causes a rapid release of catecholamines increases and a stimulation of the hypothalamic-pituitary adrenal (HPA) axis and sympathetic -adrenal medullary (SAM) axis, leading to the release of cortisol within a few hours $(31,39)$. These hormonal responses are related to the intensity and duration of PA (62). Furthermore the release of catecholamines and glucocorticoids by PA change the production of cytokines which can affect the distribution of leukocyte subtypes $(39,62)$.

Mental Health Effects of Physical Activity. The physical and social effects of COVID-19 lead to various psychological dysfunctions that can ultimately weaken the immune system (63). Regular PA reduces stress and anxiety (42). Increases in cytokine levels induced by anxiety and stress can also suppress the immune system (42), decreases in plasma ACTH and corticosterone levels which is rated to the type of PA (acute of chronic). (42, 64). Levels of monoamine neurotransmitters involved in anxiety, such as dopamine (DA), noradrenaline (NE), and serotonin (5-HT), can be modulated by PA (42, 64, 65). Brain-derived neurotrophic factor (BDNF) is a neurotrophin associated with both anxiety and depression (64). Voluntary PA for 20 days increased the levels of BDNF mRNA in the hippocampus and caudal neocortex (65).

Antioxidant Effects of Physical Activity. Oxidative stress in host cells is an important factor in the infectivity of human coronavirus (46, $66,67)$. Oxidative stress activates phagocytes and causes the release pro-oxidant cytokines such as TNF, IL-1 and IL-6, leading to the suppression of the immune system $(66,68)$. Infection of mice with influenza $\mathrm{A}$ is associated with decreased total lung glutathione concentrations and antioxidant markers such as vitamin E (37).

PA decreases oxidative stress by improving antioxidant defenses consisting of enzymes such as catalase, superoxide dismutase, and glutathione peroxidase, and non-enzymatic antioxidants including glutathione (37). Longitudinal studies suggest that PA induced reduction of oxidative stress depends on the mode, intensity and frequency of PA $(37,68)$.

Strenuous acute PA increases oxidative metabolism and induces oxidative stress, while long-term moderate PA augments antioxidant enzyme activity, leading to a greater mitochondrial capacity to scavenge free radicals and reduce free radical levels $(30,40)$. PA increases glutathione peroxidase (GPX) levels and decreases levels of creatine kinase (CK) and lactate dehydrogenase (LDH) after 1 month regular PA and sedentary group. $\mathrm{CK}$ and $\mathrm{LDH}$ enzymes are released into plasma as the result of the destruction of the cell membrane by oxidative stress or tissue necrosis (69).

Patients with COVID-19 have higher levels of LDH and CRP (45). A recent study reports that PA improves promote immune function in young males and females by regulating catecholamine concentrations, anti-inflammation and antioxidant biomarkers, LDH activity (70). The World Health Organization (WHO) has recommended exercise to combat the effects of COVID-19 (16) by stimulating the immune system and improving mental health $(31,42)$.

\section{EFFECTS OF NATURAL PRODUCTS ON THE IMMUNE SYSTEM}

The cytokine storm that occurs in COVID-19 is an inflammatory response mediated by CRP, IL-1 $\beta$, IL-2, IL-7, IL-8, IL-9, IL-10, IL-17, GCSF, GM-CSF, IFN- $\gamma$, TNF- $\alpha$, IP-10, MCP1, M1P1A, M1P1 $\beta$ (6). We describe effects of some medicinal plants and supplements on inflammatory and oxidative stress, particularly as it related to COVID19.

Curcumin. Curcumin is a yellow material found in the plant Cormonalga that possesses antioxidant, anti-infective and anti-apoptotic effects (71). The recommended dose of curcumin is 150 to $6000 \mathrm{mg}$ per day, although the European Food Safety Authority (EFSA) suggests doses of up to $3 \mathrm{mg}$ per kilogram of body weight per day (72). McFarlane and colleagues compared the effects of three doses of curcumin (200, 400, and 1000 $\mathrm{mg}$ ) on serum inflammatory cytokines and concluded that the optimal dose is $400 \mathrm{mg}$ per day (73).

Curcumin interacts with neutrophils, macrophages, monocytes, natural lethal cells (NK), dendritic cells (DC), and B and T cells and affects innate and adaptive immunity (74). The inhibitory effects of curcumin on the proliferation of immune cells is dose- and time-dependent (73, 74). Curcumin also prevents the activation, differentiation and production of cytokines by 
suppressing immune responses in T cells (71) and regulates genes for $\mathrm{c}-\mathrm{MYC}, \mathrm{BCL}-\mathrm{XL}$, and NFkB (73-75). Curcumin reduces the inflammation of the lungs caused by the flu virus by inhibiting the NF-kB pathway, reducing the activation and polarization of macrophages (75) and altering the proliferation and oxidative function of macrophages by inhibiting the TLR 4 pathway. Curcumin increases IgA levels and suppresses its degradation, leading to increased immune function in animals consuming a high fat diet (76) and also increases Th1 production $\mathrm{CD} 4+$ and CD8 + counts (77).

The possible that the beneficial effects of curcumin supplementation in the inflammatory process may be due to the inhibition of NF- $\kappa \mathrm{B}$, signal converter and Janus kinase transcription activator (JAK / STAT) and mitogen activated kinase protein (MAPKs) signaling pathways and inhibition of TNF- $\alpha$, IL-1, -2, -6, -8, -10 production (78). Curcumin suppresses leukocyte infiltration, activation, and maturation, and also the production of inflammatory mediators (TNF$\alpha$, CRP, IL-8, and IL-6) and nitric oxide synthase activity (78).

Curcumin modulates the expression of chemokines such as IL-6, IL-10, IFNc, and MCP1 which participate in ARDS in lung tissue Curcumin also reduces TGFß II receptors and inhibits the expression of smooth muscle actin and tenascin-C (indicators of myofibroblast activation) $(79,80)$. This data strongly supports the important role of curcumin in modulating inflammation and differentiation of myofibroblasts in the pathogenesis of ARDS caused by viruses in a preclinical models $(79,80)$.

Nasal administration of curcumin reduces allergic airway inflammation and inhibits structural integrity in mice with allergic asthma by modulating cytokine levels (IFN-1, 5, IL-4, and TNF- $\alpha$ ) and phospholipase A2 to inhibit the release of PGD2 $(71,81)$. In addition, curcumin suppresses ERK 42/44, P38 MAPK and JNK $54 / 56$ activation in mice with advanced asthma (71, 81). Cytokines such as IL-10 inhibit the synthesis of inflammatory cytokines such as CRP, IL-6, and TNF- $\alpha(73,82)$. Higher levels of IL-10 and IL1RA have been reported in curcumintreated groups $(73,82)$.

Curcumin inhibits lipid peroxidation, and protect cell membranes from oxidative damage; . this inhibition of lipid peroxidation results from curcumin binding to iron and also by increasing the activity of superoxide dismutase (SOD) and glutathione peroxidase (GPx), (77). Curcumin reduces chronic stress-induced oxidative damage in the brain, lungs, liver and kidneys (83).The effects of curcumin on the immune system suggests that it may have potential use in supporting treatment strategies for COVID-19.

Black Cumin. Black seed (or also knows as black cumin, kalonji) is derived from Nigella Sativa the plant family Ranunculaceae (84). The seeds of this plant contain amino acids, proteins, carbohydrates and volatile oils ( 0.5 to a maximum of $1.5 \%)$ and non-volatile or fixed oils (30\%). Black cumin has antibacterial, antifungal, antischistosomiasis, antioxidant, anti-diabetic, anticancer, anti-inflammatory and analgesic properties, and interact with the immune, cardiovascular, gastrointestinal, hepatic and renal systems (85).

Administration of black cumin oil and black cumin polyphenols produces analgesic and antiinflammatory effects in mice (86), likely due to inhibition of the cyclooxygenase and 5lipoxygenase pathways (87). Black cumin has beneficial effects on the respiratory tract and lung parenchyma (88) as shown by improvements of respiratory disorders such as asthma and bronchospasm, possibly due to inhibition of histamine release (89). Numerous studies have examined the anti-inflammatory and anti-asthma effects of black seed $(90,91)$, as shown by the ability of black seed extracts to reduce lung remodeling, preventing endothelin 1 release and improve metaloproteinase matrix 3 (MMP3) and growth factors generation (92).

It is possible that consuming black cumin could be improve symptoms of Covid-19. The protective effect of Nigella sativa extract on lung inflammation and oxidative stress was recently demonstrated in a study in rats treated with lipopolysaccharide (LPS), where it also limited tissue damage (93). LPS increases counts of WBC, eosinophils, neutrophils, basophils, and monocytes, and of oxidative stress markers in bronchoalveolar fluid and serum, and levels of TGF- $\beta 1$, IFN- $\gamma$, PGE2, and IL-levels (93).

Adiantum Capillus-Veneris. Adiantum capillus-veneris is perennial herbaceous plant of the ferns family, with a rhizome (underground root stem) brown, narrow and knotted, and narrow and thin roots (94). This plant has threepart leaflets and the leaves very narrow branched 
to brown or dark purple. One of its main characteristics is the Haggins, which are seen in the tip of the leaflets as prominent, green or brown spots (94). The chemical compounds in this plant include Mucilages, sugar, coffee acid, gallic acid and a bitter substance called Capillarine (94). New studies show that there are substances called Triterpene oxide, Flavonoids, Astragalin and Tannin in this plant, as well as biologically active substances such as Triterpenoids, Olean, Phenylpropanoids, Carotenoids and Alicyclics (94).

In a study of plant composition in northern Iran based on phytochemical tests, it was found that this plant contains tannins, flavonoids, terpenoids and unsaturated sterols (95). Separation of active ingredients was based on the presence of terpenoids and unsaturated sterols. For this purpose, chromatographic method was used on the column. With this method, three compounds were separated from the plant, the structure of which was identified using the results obtained from the mass spectra of infrared (IR) and (PMR) mass and elemental decomposition. These compounds include: 1) Isobaurenol with a closed formula $(\mathrm{C} 30 \mathrm{H} 50 \mathrm{O})$ and a molecular mass of 426. 2) a derivative of isoburonol with an epoxy structure with a closed formula $(\mathrm{C} 29 \mathrm{H} 48 \mathrm{O})$ and a molecular mass of 412. terletala terimet (3) D methyl terephthalate. With closed formula (C10H10O4) and molecular mass $194(95,96)$. The extract of this plant is used as an herbal medicine and emollient to soothe and strengthen the breast. Adiantum capillus-veneris has a long history in pharmaceutical use and its main ingredients have been used in cough syrup called capillaire in the nineteenth century (97, 98). Oxidative stress refers to a condition in which the biological system's ability to detoxify or repair the destructive effects of a variety of oxygen free radicals is insufficient, leading to oxidative damage to cells, tissues or organs of the body, and macromolecules such as DNA, Carbohydrates and protein. Cellular antioxidants significantly delay or inhibit the oxidation of macromolecules (97, 98).The extract of Adiantum capillus-veneris leaves provides membrane passage in laboratory conditions and neutralizes free radicals (98). Free radicals cause damage to lipid peroxidation in the DNA and membranes of living organisms, leading to various diseases. Antioxidants neutralize the effects of free radicals in various ways and may prevent various diseases in the body(98). Inoculation (perineal period) of peripheral blood lymphocytes with $\mathrm{H} 2 \mathrm{O} 2$ (hydrogen peroxide) for 2 hours dramatically increases lipid peroxidation and reduces glutathione levels and antioxidant enzymes (94). But the extract of Adiantum capillus-veneris leaves effectively prevents lipid peroxidation and significantly increases the antioxidant enzyme activity and glutathione content. Toxic compounds with free radicals are usually combined with glutathione and removed from the body (94). In 2009, Kumar studied the effects of Adiantum capillus-veneris antioxidants on human lymphocytes in the laboratory (98). This study surveyed the potential antioxidant effects of this plant on hydrogen peroxide due to oxidative stress that causes damage to peripheral blood lymphocytes (98). Environmental blood lymphocyte incubation with $100 \mathrm{mM}$ of hydrogen peroxide for 2 hours significantly increased lipid peroxidation and reduced glutathione levels and antioxidant enzymes (SOD, CAT, GPX). Adiantum capillus-veneris leaves extract was able to significantly prevent lipid peroxidation and improve the activity of antioxidant enzymes and glutathione content. Free radicals caused by lipid peroxidation cause damage to cell membranes and DNA (98). In order to investigate the antiinflammatory effect of ethanolic extract Adiantum capillus-veneris L, a study conducted by Qianing Young et al. (2013) Showed that NF$\kappa \mathrm{B}$ signaling in stimulated cells may help to the underlying mechanism of observed antiinflammatory potential (97). Most importantly, since Adiantum capillus-veneris plant extracts suppress inflammation in CD-1 mice caused by LPS (lipopolysaccharide) without liver and heart toxicity, Adiantum capillus veneris is a promising drug for the treatment of inflammatory diseases (97). In another study by Yadegari et al., the effect of chronic hypoxia and Adiantum capillusveneris supplements on protein response of P53, TNF-a and exercise -related respiratory changes were investigated and was shown that 3 weeks of exposure to hypoxia, after 6 weeks of exercise, increased P53 and TNF-a and decreased respiratory rate. After 3 weeks of taking Ac-v extract during exposure to hypoxia, the levels of P53 and TNF-a decreased and the level of respiration increased (95).

According to the results of studies, Adiantum capillus veneris by inhibiting free radicals and anti-inflammatory effects, leads to the 
improvement of the body's immune system, and through this, the body can be protected against various virus and infectious diseases such as COVID-19.

Thyme. Thyme is a herbaceous plant with the scientific name of thymus vulgaris and is green and fragrant (99). This plant is the most wellknown medicinal plant that has high antioxidant properties and there are various species that have been considered by researchers. Antiinflammatory, antibacterial, antiseptic, antispasmodic, antioxidant, anti-cough and performance enhancer Immune system is one of the remarkable properties of this medicinal plant (100). The medicinal parts of this plant include its branches and dried leaves (aerial parts), which contain various compounds, the most important of which are thymol and carvacrol (101). The medicinal parts of this plant include its branches and dried leaves (aerial parts), which contain various compounds, the most important of which are thymol and carvacrol. Naturally, thymol is the main component in thyme and carvacrol is also a sub-component (101). The biological and therapeutic effects of this extract are mainly attributed to these compounds (101). This plant has a positive therapeutic status in the German Pharmaceutical Commission and ranks first in the Commission of the World Health Organization (101). Thyme extract has been used in traditional medicine to treat several respiratory ailments such as asthma and bronchitis (102) and to treat other injuries caused by the properties of this plant such as antiseptic, antispasmodic, antifungal, antioxidant and antivirus $(103,104)$. Thyme oils have also been described as a potent bactericide against positive (GARM p) and negative (GARM n) bacteria as well as a bronchospasmolytic (105). However, little research has been done on the anti-inflammatory activity of thyme. For example, thyme oil has been reported to produce NO in mice J774A.1 (106). The biological activity of medicinal plants depends on their composition. The most important compounds are thyme, carvacrol and thymol $(107,108)$. Timol has several biological activities, including antiinflammatory effects (109), strengthening the immune system (110), antioxidant effects (111), antibacterial, antifungal (112), and free radical improvement (113). Carvacrol also has antimicrobial, antifungal, antioxidant antiseptic and anti-cancer activities (114-117). The therapeutic effect of thyme and oregano oils that containing thymol and carvacrol as their main compounds in colitis mice has been observed with decreased levels of pre-inflammatory cytokines IL- $1 \beta$, IL- 6 and TNF- $\alpha$. However, the mediating mechanisms of these repressive effects are unclear (104). Bornol, another ingredient in thyme, has been described as an antiinflammatory because its dietary supplements significantly reduce the concentration of preinflammatory cytokines IL- $1 \beta$, CRP and IL- 6 in mice (118).

Three different species of thyme (Thymus vulgaris, Thymus zygis and Thymus hyemalis) were identified by GC-MS. The main constituents of thyme include thymol, 1,8-cineole, carvacrol, and bidol (119). Treatment of activated cells with thyme was resulted to overall reduction depending on Dose in the release of preinflammatory cytokines, TNF $\alpha$, IL-1 $\beta$, and IL-6, and a group was treated with some diclofenac (5 micrograms per million liters) $(120,121)$. In general, thyme extract has a better antiinflammatory effect at lower concentrations, reducing pre-inflammatory cytokines (TNF- $\alpha$ and IL-1 $\beta$ ) more than diclofenac, and increasing IL10 anti-inflammatory factor that was not associated with Diclofenac treatment (122).

After 24 hours of incubation, the treated activated cells with each of the thyme sections showed a significant decrease in TNF- $\alpha$ emission compared to the untreated cells. Both Thyus zygis and Thymus vulgaris had similar effects on TNF$\alpha$ secretion. For concentrations of $15 \mu \mathrm{g} / \mathrm{ml}$ and above, the TNF- $\alpha$ decrease was such that the cytokine level was much lower than the inactive baseline level. For thymus hymalis, TNF- $\alpha$ secretion was less than the inactive control group for injectable concentrations of $25 \mu \mathrm{g} / \mathrm{ml}$. Despite a sharp decrease in TNF- $\alpha$ secretion in 24-hour treatments, treatment with injections Thymus zggis and vulgaris for 48 hours showed a decrease in TNF- $\alpha$. For this section, only a concentration of $25 \mu \mathrm{g} / \mathrm{ml}$ has significantly reduced the TNF- $\alpha$ level, equal to the inactive base level $(106,109)$.

Thyme had antagonistic effects on the antiinflammatory cytokine IL-10. 24-hour treatment with each of the sections increased the dosedependent IL-10 secretion. Higher injection concentrations cause more IL-10 secretion. Thyus zygis and Thymus vulgaris were more effective than Thymus hyemalis. In the case of Thymus hyemalis, the increase in IL-10 secretion was less 
and was significant only when 15 micrograms per milliliter or higher concentrations were injected. Also, TNF- $\alpha$ did not change with extract. Only Thymus hyemalis S2 significantly reduced cytokine gene expression $(106,109)$.

Cytokines play an important role in the inflammatory response involved in atherosclerosis and other chronic inflammatory diseases (CIBD) such as covid19. Among these cases, interleukin IL-1b, IL-6, IL-10, and tumor necrosis factor $(\alpha)$ (TNF- $\alpha$ ) are expressed in atherosclerotic lesions by endothelial cells, macrophages, and smooth muscle cells $(123,124)$.

Some of them are involved in protogenic processes, such as the re-regulation of adhesion molecules on endothelial cells, and have also been shown to have anti-autogenic roles, such as reducing the differentiation of monocytes in macrophages. Both IL-1 and IL- 6 enhance the inflammatory process. Imbalance in the expression of cytokines is involved in the development of many diseases, including CIBDs (125). Cytokines have pathological and beneficial effects on their target cells and are produced by many cell types (126).

Thyme appears to cause exppresion preinflammatory cytokine TNF- $\alpha$, IL- 6 and IL- $1 \beta$, and anti-inflammatory cytokine IL-10. The amount of pre-inflammatory cytokines decreased with consuming Thymus vulgaris, Thymus zygis, or Thymus hyemalis (after 24 or 48 hours of incubation). These results were consistent with the results of cytokine gene expression in 24 hours of incubation (127). Due to the independent effect of thyme on immune, infectious and disease-related symptoms, this plant can be considered effective in these functions.

Ginger. Ginger is the root of fresh or dried zengiber officinale. Ranjil powder and is used to treat flu and appetite, or as an anti-inflammatory agent in the treatment of migraine headaches (128). Ginger compounds include carbohydrates, free fatty acids, amino acids, protein, phytosterols, vitamins, such as niacin, vitamin C components (folic acid, inositol, choline and pentonic acid), vitamins B3 and B6, and essential nutrients Such as calcium, magnesium, phosphorus and potassium $(129,130)$. This spice is used as an antioxidant and to reduce the pain caused by osteoarthritis. 6- Shogawaol (1-4hydroxy-3-methoxy-4-desen-1) is one of the important compounds in ginger. It has been reported that this plant has antipyretic and analgesic effects, as well as inhibitory effects on lipoxygenase activity, which has antiinflammatory properties in ginger powder (131). Ginger extract has antioxidant properties and neutralizes superoxide anion and hydroxyl radicals. The main antioxidants in ginger include gingerol, shogawaol, zingerun, and a number of phenolic ketone derivatives that have been shown in the laboratory to have many pharmacological and physiological activities such as antiinflammatory, analgesic, anticarcinogenic, and cardiototonic effects. Ginger also decrease serum glutamate oxaloacetate transaminase (GOT) levels and glutamate pyruvate transaminase (GPT) (132). Ginger reduces lipid peroxidation and free radicals by reducing malondialdehyde (MDA) and increasing plasma antioxidant capacity. Malondialdehyde is the most important sign of lipid peroxidation (133). Various researchers have confirmed the antioxidant properties of ginger and the elimination of superoxide anion and hydroxyl radicals. Therefore, the anti-inflammatory effect of ginger may be due to a decrease in the formation of prostaglandins and leukotrienes (133). Ginger has also been shown to inhibit the metabolism of arachidonic acid, which has anti-inflammatory properties. One of the mechanisms of inflammation is metabolized oxygenase and prostaglandin E2 and leukotriene B4, which are the two mediators of inflammation. Ginger contains chemicals that have anti-inflammatory potential, and these effects may be due to the effects of gingerols, shogavols, di-aryl heptanoids, and dialdehyde diprenes, which inhibit inflammatory prostaglandins (134). Sudipa Tripati et al. Observed that ginger extract stimulate IL-12, TNF- $\alpha$, IL-1 $\beta$ (inflammatory cytokines) and RANTES, MCP-1 in LPS macrophages. Ginger extract also regulated the expression of B7.1, B7.2 and MHC class II molecules (135). In addition, ginger extract had a negative effect on antigen performance in macrophages and saw a significant reduction in $\mathrm{T}$ cell proliferation in response to threshold, when ginger-treated macrophages were used as APCs. Significant reductions in IFN- $\gamma$ and IL-2 production were also observed by $\mathrm{T}$ cells in response to the simulation threshold (135). In herbal medicine, this herbal supplement has been used to treat influenza and viral and infectious diseases due to its anti-inflammatory and antioxidant properties. 
Cinnamon. Cinnamon is the dried and peeled pieces of cinnamomum tree bark, which is used as a spice and medicine. Cinnamon contains amidone, mucilage, tannin, a pigment, calcium oxalate, sugar, cinnamomine and resin (136). The main component of cinnamon essential oil is cinnamaldehyde and 5-18\% eugenol. Cinnamaldehyde essence has been reported to have an antispasmodic effect on cinnamon. Pharmacological and toxicological research does not pose a risk to human consumption of cinnamon. Cinnamon has the healing properties of carminato, antimicrobial, antioxidant, antiviral and antispasmodic antidiabetic anti-flatulence, antiperspirant, warming and stimulates the uterus (137). There have also been reports of liver cell swelling, increased stomach thickness, and nephritis following long-term use of cinnamon, which has been attributed to its essence (138). The main constituents of cinnamon are $80-95 \%$ cinnamon aldehyde, which is the taste of cinnamon due to this substance, 5\% cyanoyl acetate, $4 \%$ agnol, 3\% cariopylen, $2 \%$ linalool, $0.7 \%$ alpha alpha triplene, $0.7 \%$ Coumarin, $0.6 \%$ and 8-cineole and $0.4 \%$ terpene-4L. Cinnamaldehyde is the main ingredient in cinnamon essence (139). The antioxidant properties of cinnamon extract have been proven during research. aldehyde, gammaagenol, 4terpineol, terpinene, and camfen are among the phenolic and non-phenolic compounds of cinnamon that have antioxidant properties (140). Also, some of the phenolic and non-phenolic and non-volatile compounds of cinnamon shells that have antioxidant properties include cinacacilli, beta-cystrol, epicatechin, creatinine, syringic acid, cinnamic acid, coumarin and vanillic acid (140). In a recent study by Robert Ossie et al., The addition of cinnamon supplementation significantly inhibited the maturation of DC dendritic cells and inhibited the proliferation of specific T cells, such as the production of Th1 and Th2 cytokines (141). The release of sulfidololcuterin and CD63 expression by basophils was also significantly reduced after the addition of ethanolic cinnamon extract (CE). Treatment of OBA-sensitive mice (OVA) with $\mathrm{CE}$ resulted in a significant shift from OVAspecific $\operatorname{IgE}$ to $\operatorname{IgG} 2 \mathrm{a}$ production and severe inhibition of specific OVA proliferation (141). In addition, inflammation of the airways as well as anaphylaxis is reduced after the challenge of intrauterine or systemic in mice treated with $\mathrm{CE}$.
In general, the anti-inflammatory effect of cinnamon may be used to treat allergic inflammation (141).

Zinc. Zinc is an important nutrient for maintaining hemostasis in the immune system, and zinc deficiency can impair the function of the immune system (142). Zinc deficiency is associated with an increased risk and severity of common infections in children, such as diarrhea and pneumonia, in low-income countries around the world (143). It is a transfer metal that plays an important role in the function of many proteins (144). Zinc intracellular displacement may facilitate the rapid signaling of intracellular signaling in immune cells by facilitating the movement of ions between the intracellular space and the cytoplasm (145).

Previous studies in both early rat and human monocytes have shown that zinc deficiency impairs TLR4 receptors and thus reduces the response to bacterial LPS, which reduces generally phagocytic activity and production of cytokines such as IL- $1 \beta$, TNF- $\alpha$, IL-6, and IL-10 $(145$, 146). In addition, zinc deficiency significantly reduces $\mathrm{T}$ cell count and causes thymus atrophy.Zinc deficiency also impairs $\mathrm{T}$ cell function and impairs $\mathrm{T}$ cell cell receptor (TCR) signaling, thereby reducing $\mathrm{T}$ cell proliferation and producing cytokines in response to TCR signaling $(147,148)$. Studies in humans have shown that deficiencies disrupt cytokine production (Th1, IL-2, TNF- $\alpha$ and IFN- $\gamma$ ), while having less effect on Th2 cytokine production (IL-4, IL- 6 and IL-10) (89), so it affects the Th1 / Th2 balance. Numerous studies have reported that these regulated disorders are repaired by zinc supplementation (149). In some cases, zinc therapy in vivo and in vitro reduces immune responses through Th cells (eg, Th2 allergic responses and Th17 autoimmune responses) and increases the number and activity of T regulatory cells (Treg) (150). The effects of zinc deficiency on immune function may be somewhat effective in increasing the risk of infection and the entry of a variety of viruses into the body (151).

A study by Chidchamai et al. showed that zinc supplementation in Laotian rural children had no effect on cytokines or $\mathrm{T}$ cell concentration, although the supplement did affect lymphocyte and eosinophil concentrations. These cellular subsets may be useful as indicators of zinc supplementation (152). In another study conducted by Martina Mayward et al., 2017, it 
was concluded that all immune cells are directly affected by zinc signals. The most important pathological changes during zinc deficiency indicate that it is the main regulator of cell function and signal transmission. However, the underlying molecular mechanisms still need to be examined in more detail to ensure the beneficial effects of zinc application on patients with different diseases (145).

Vitamin C. Vitamin C is an essential nutrient that cannot be synthesized by humans due to the loss of a key enzyme in the biosynthetic pathway $(153,154)$. Severe vitamin C deficiency leads to potentially fatal disease Vitamin $\mathrm{C}$ deficiency leads to weakening of collagen structures, improved wound healing and immunity (155). People with vitamin $\mathrm{C}$ deficiency are more prone to potentially fatal infections such as pneumonia (156). Infections can affect vitamin $C$ levels due to increased inflammation and metabolic needs (156). Although the amount of vitamin $C$ needed to prevent scurvy is relatively low (ie $10 \mathrm{mg}$ per day) the recommended diet for vitamin $\mathrm{C}$ is higher than many other vitamins $(157,158)$. A diet of 100-200 mg per day provides vitamin C saturation of plasma concentrations in healthy individuals and covers general needs to reduce the risk of chronic disease (159). Vitamin $\mathrm{C}$ has several activities that can significantly play a role in modulating the body's immune system. Due to its ability to donate electrons quickly, it is known to be a very powerful antioxidant, so it is one of the most important biomolecular molecules (proteins, lipids, carbohydrates and nucleic acids) against the damage of oxidants created during cellular metabolism and exposure to toxins and contaminants protects (160).

Vitamin $\mathrm{C}$ is also an effective factor in a family of enzymes that regulate biosynthesis and the gene that regulates monoxygenase and dioxygenase (161). Vitamin C enhances phagocytosis and ROS production enhances the effect of microbial lethality, and in the case of $\mathrm{T}$ and B lymphocytes, distinguishes and multiplies and enhances antibody levels (162-164) It also modulates the production of cytokines in relation to inflammatory mediators and reduces histamine levels $(164,165)$. Vitamin $C$ appears to have beneficial effects on the cellular functions of the innate and adaptive immune system (166). Although vitamin $C$ is a powerful antioxidant that protects the body against endogenous and exogenous oxidative challenges, its high performance as a cofactor for many biosynthetic regulatory enzymes and regulatory genes is likely to play an important role in immune system modulating effects (166). Vitamin C stimulates the migration of neutrophils to the site of infection, enhances phagocytosis and oxidative production, and kills germs (166). At the same time, by strengthening the neutrophil apoptosis by macrophages, and reducing the neutrophil necrosis, it protects the host tissue against overuse (166). Therefore, it is clear that vitamin $\mathrm{C}$ is necessary for the body's immune system to provide a sufficient immune response to pathogens and at the same time to prevent excessive damage to the host (166) It seems that vitamin $\mathrm{C}$ can prevent and treat respiratory and systemic infections by strengthening the various functions of immune cells. To prevent infection with vitamin $\mathrm{C}$ in the diet, 100-200 mg per day is sufficient that not saturate the plasma surface and optimize the cell and tissue levels (166).

Epidemiological studies show that hypovitaminosis $\mathrm{C}$ is still relatively common in Western populations, and vitamin $\mathrm{C}$ deficiency is the fourth leading nutrient deficiency in the United States (166). The reasons include reduced consumption along with increased needs due to pollution and smoking, fighting infections and diseases with oxidative and inflammatory components, for example, type 2 diabetes and so on. Ensuring adequate vitamin $\mathrm{C}$ intake through diet or supplements, especially in groups such as the elderly or other people who are exposed to insufficient risk factors for vitamin $\mathrm{C}$, is essential for proper immune function and resistance to infections (166).

Although information on vitamin $\mathrm{C}$ intake during the outbreak of COVID-19 is contradictory, in one study, Orwell examined the mechanisms of vitamin C's effectiveness in preventing corona. He said that vitamin $\mathrm{C}$ can greatly reduce the risk of COVID-19 by boosting and improving the immune system and its antiinflammatory and antioxidant effects (167).

Garlic. Garlic, scientifically known as Allium Sativum, is a medicinal plant in the category of onion vegetables that contains about $65 \%$ water, $2 \%$ protein, $1.5 \%$ fat and $28 \%$ carbohydrates (168). Garlic is one of the medicinal plants that has been used for food and medicine for many years and contains various compounds such as organosulfur, amino acids, vitamins and minerals that have antimicrobial, anti-inflammatory, anti- 
clotting, anti-tumor and anti-oxidant, cholesterol and blood glucose lowering properties (168). Some sulfur-containing compounds, including Allicin, S allyl cysteine, and dialyl disulfide, are responsible for the healing properties of garlic. Allicin is known to be the most important biologically active component of garlic (168). Today, garlic is known to be one of the most important factors in maintaining the immune system (168). Its effects on the immune system include modulation of cytokine secretion, promotion of phagocytosis and activation of macrophages, production of immunoglobulin, control of allergic reactions and proliferation of lymphocytes.

According to studies, garlic-derived compounds including S-allyl-L-cysteine (SAC), caffeic acid (CA), uracil, diallyl trisulfide (DATS) known as alitridin and diallyl sulfide (DAS) by inhibiting the main regulatory factor Inflammation, NF- $\kappa \mathrm{B}$, inhibits the expression of several cytokine genes involved in inflammatory responses, including TNF-1, IL- $1 \beta$, IL-6, MCP1, and IL-12 (168).

The allicin in garlic increases the expression of $\mathrm{CD} 4+\mathrm{T}$ cells (CD4 $+\mathrm{T}$ cells) and macrophages. It has also been observed that the allicin in garlic controls the parasitic infection by modulating the cytokines that activate macrophages (168). Researchers have shown that dietary supplementation, by increasing the proliferation of $\mathrm{T}$ cells, directly and indirectly increases the proliferation and differentiation of $\mathrm{B}$ cells and can be involved in the production of immunoglobulin (168).

On the other hand, lectin in garlic appears to release histamine from mast cells and basophils by interacting with $\operatorname{IgE}$ molecules at the cellular level (169). Clement et al. Isolated three immune system regulatory proteins (QR-1, QR-2, and QR3 ) from raw garlic. QR-2 releases high levels of histamine from leukocytes due to the activation of mast cells and basophils (169).

In a study, Mehrbod et al.(2009) Investigated the antiseptic and antivirus effects of garlic extract on the flu virus (170). They showed that the antiviral effects of garlic extract were observed by reducing the concentration of cytokines during infection, so they introduced garlic as a potent disinfectant during infection (170). One study looked at the anti-inflammatory effects of fresh and warm raw garlic extract (FRGE and HRGE) on producing NO-induced
LPS and inflammatory cytokines due to decreased alisin function in RAW 264.7 macrophages, results showed that the anti-inflammatory effect and Alicin concentration was more in FRGE than HRGF (171). Therefore, the reduction in NOinduced LPS and anti-inflammatory cytokines in RAW 264.7 macrophages was greater through HO1 induction for FRGE compared to HRGE (171).

Beeswax and Honey. Beeswax, which is obtained from the melting of bees' nests, is a yellow, soft, and highly absorbable substance that is usually produced by bees. Waxes contain esters, fatty acids and alcohols, and slightly free hydrocarbons of protein, fiber, minerals, vitamins, and glycosidic flavonoids, and 50 uromatic substances, and are also used for pharmaceuticals (172). Propolis is also a gum substance that bees collect from different plants. The chemical composition of propolis is qualitatively and slightly different and will depend on the plants in that area. Propolis contains a lot of nutrients that are very strong due to the abundance of energy and protein (173). It also has antimicrobial, antifungal and immuneboosting properties. Naturally, propolis is made up of $30 \%$ wax, $50 \%$ gum, $10 \%$ essential fats, aromatic and herbal fragrances, and 5\% polen (173). Polyphenols are pharmacologically active components of propolis due to their ability to inhibit a variety of enzymes and are considered in this regard. Clinical studies have also shown that propolis contains high concentrations of flavonoids, which are widely used to produce drugs due to their antimicrobial properties (174). A study entitled the effect of propolis and its isolated compounds on the production of cytokines by macrophages showed that propolis inhibited IL-6 production (175). Depending on the concentration, propolis regulates the immune / inflammatory response. Its efficiency may be due to the increasing effect of its compounds and may play a role in the production of cytokine in propolis (175).

Honey is a delicious and amazing food that bees produce using flower nectar, which has been studied in various studies, including antibacterial effects (176), strengthening the immune system (177), and respiration (178, 179). antioxidants and recent studies have also shown antitussive effects $(178,180,181)$. Another review study found that the effect of dextromethorphan on cough in adults and the effect of honey on cough 
in children compared with placebo had not been shown to have a better effect in reducing the cough in children than in placebo (182). Moderate, decreased severity and frequency of cough compared with dextromethorphan or no medication (182). Therefore, in addition to its antimicrobial, antifungal, antibacterial and antivirus effects, honey has been introduced by the British Public Health Service (PEH) as a treatment for acute coughs caused by upper respiratory tract infections (180). It is also one of the major symptoms in patients with COVID-19. Therefore, this nutrient can be considered as one of the treatment strategies as well as the prevention of this disease.

Selenium. Selenium, abbreviated Se, is widely found in soil, plants, and grains, and has a wide range of commercial uses, including shampoos, photocells, and as an anti-inflammatory agent (Selectoc) (183). The biological necessities of Se were first recognized by Schwartz and Voltz (1957), but clear evidence for its function as a key element was provided by Thompson and Scott (1970) (183).

Selenium (Se) is a powerful nutritional antioxidant that combines its effects on selenoproteins to have biological effects. Given the important roles that selenoproteins play in regulating reactive oxygen species (ROS) and redox status in almost all tissues, it is not surprising that the SE diet strongly influences inflammation and immune responses (184).

Using studies on aging or immunity protection against pathogens, selenium strengthens the immune system (184). The immune system is a very special defense mechanism that recognizes and kills nonnative cellular and non-cellular organisms. This process requires specific antigen detection at the molecular level and a complex network of functional immune cells (183). Recent evidence suggests that Se significantly affects the function of all components of the immune system, namely non-specific, humoral and cellular mediators (183). The effects of Se on important safety functions indicate that trace element tracking through its ability to enhance and / or restore effective mechanisms or mediators of host defense, as a safety response modifier, may be of high clinical significance (183).

Lemon. Lemon or Citrus limonum is the sour fruit of the Rutaceae family, which has volatile oil. It was first cultivated in China and India and has gradually spread to other countries. Lemon has been considered for its high content of organic acids, especially citric acid, and for creating acidic conditions in the treatment of many inflammatory and infectious diseases. It has also been widely used in epidemics such as cholera in various parts of the world, as it has high antimicrobial properties against the bacterium that causes the disease (Vibrio cholerae) (185, 186). Sour lemon essence, which is obtained by squeezing the outer part of fresh sour lemon peel, contains 95-92\% of various terpenes. Most of it is limonene with Baflander, Camfen, and Pienen. The pleasant smell of lemon essence is related to the presence of citrate, which is found in the amount of $4-7 \%$. In addition, it contains free geraniol, linalool, citronellol and a small amount of nonylide and antranilic acid (187).

Vitamin $\mathrm{C}$ is a powerful antioxidant that, in addition to eliminating harmful cells and free radicals in the body, prevents the formation of cancer cells and cancer (188). Vitamin C and the antioxidants in sour lemons help to eliminate toxins from the body caused by a variety of contaminants such as lead or dust in the air. Sour lemon is a great source of vitamin B complex and a precursor to vitamin $\mathrm{A}$. These vitamins increase the body's immunity. Lemon has a very high fiber, which has been very helpful in maintaining good health. Citric acid in lemon helps digestion (188). Lemon is very useful for irregular heart movements caused by improper digestion and liver toxins. The acids in lemons decrease uric acid and dilute the blood. Sour lemon lowers blood cholesterol levels. Lemon also improves normal and migraine headaches (188). The bioflavonoids in lemons reduce the brittleness of capillaries. People who suffer from sciatica should eat a lemon before a meal. Sour lemon is also effective in improving memory enhancement (188). A study examining the protective effect of lemon on inflammation and oxidative stress in rats showed that malondialdehyde levels, alpha tumor necrosis factor (TNF-a), C-response protein and leptin in the sour lemon supplement group in the comparison with the control group was significantly lower (189). Lemon juice in all three doses significantly improved serum levels of TAC, MDA, TNF $\alpha$ and hs-CRP in the treated groups. Consumption of $7.5 \mathrm{ml}$ of lemon juice also significantly reduced leptin levels. However, lemon juice did not have a significant effect on adiponectin levels. This study suggests that lemon juice as a potential dietary alternative can reduce 
leptin levels and oxidative and inflammatory damage in mice (189).

Magnesium. Magnesium plays a key role in many cellular responses. More than 300 metabolic reactions require magnesium as a cofactor (190). Magnesium is involved in many processes affecting muscle function, including muscle contraction, protein synthesis, oxygen consumption, energy production, and fluid balance, and is a physiological regulator of cell membrane strength and neuromuscular, cardiovascular, and immune function (191). However, magnesium deficiency is often found in industrialized countries. Numerous studies have reported that athletes may also be deficient in magnesium. Clinical signs of inflammation was one of the early signs of magnesium deficiency in rats. Immunosuppression of immune cells, such as monocytes, macrophages, and polymorphonuclear neutrophils, which produce a variety of biological substances, is also another sign of magnesium deficiency. Some of these cells are powerful inducers of inflammation (cytokines, free radicals, eicosanoids) (192). Large amounts of circulating cytokines such as IL-6 can be detected early in the magnesium deficiency diet and lead to the release of acute phase proteins by the liver (192). It has been observed that under laboratory conditions, high magnesium concentrations reduce the activation of human leukocytes. Extracellular magnesium can also prevent the activation of leukocytes through calcium, as magnesium is neutralized in many physiological and pathological processes by calcium. The inverse correlation between magnesium uptake and plasma CRP levels has also been observed (193). Magnesium can also reduce anxiety and stress by suppressing the hormone adrenaline, and can be very helpful in stressful situations related to the spread of covid19 disease (194).

Because magnesium is involved in a wide range of biological activities, it can be a protective factor against asthma and chronic airway obstruction. In a study, Britton et al. Showed that daily magnesium intake for 12 months in adults aged 18-70 years improved lung function and reduced the incidence of chronic airway disease and wheezing (194).

\section{CONCLUSION}

There are currently no approved drugs to treat COVID-19. The drugs available for COVID-19 primarily act as a protease. Herbal medicines and supplements studied in this study can act as COVID-19 inhibitors through anti-inflammatory, Antioxidants effects, as well as boosting the immune system. However, further research on the dosage and other possible uses of these supplements is necessary for patients with COVID-19.

\section{REFERENCES}

1. van der Hoek L, Pyrc K, Jebbink MF, Vermeulen-Oost W, Berkhout RJ, Wolthers KC, et al. Identification of a new human coronavirus. Nat Med.2004;10(4):368-373. doi: 10.1038/nm1024 pmid: 15034574

2. Hui DS, E IA, Madani TA, Ntoumi F, Kock R, Dar O, et al. The continuing 2019-nCoV epidemic threat of novel coronaviruses to global health - The latest 2019 novel coronavirus outbreak in Wuhan, China. Int J Infect Dis. 2020;91:264-266. doi: 10.1016/j.ijid.2020.01.009 pmid: 31953166

3. Huang C, Wang Y, Li X, Ren L, Zhao J, Hu Y, et al. Clinical features of patients infected with 2019 novel coronavirus in Wuhan, China. Lancet. 2020;395(10223):497-506. doi: 10.1016/S01406736(20)30183-5 pmid: 31986264

4. Lu H, Stratton CW, Tang YW. Outbreak of pneumonia of unknown etiology in Wuhan, China: The mystery and the miracle. J Med Virol. 2020;92(4):401-402. doi: 10.1002/jmv.25678 pmid: 31950516

5. Zhang H, Penninger JM, Li Y, Zhong N, Slutsky AS. Angiotensin-converting enzyme 2 (ACE2) as a SARS-CoV-2 receptor: molecular mechanisms and potential therapeutic target. Intensive Care Med. 2020;46(4):586-590. doi: 10.1007/s00134-020-05985-9 pmid: 32125455

6. Li G, Fan Y, Lai Y, Han T, Li Z, Zhou P, et al. Coronavirus infections and immune responses. J Med Virol. 2020;92(4):424-432. doi: 10.1002/jmv.25685 pmid: 31981224

7. Corman VM, Muth D, Niemeyer D, Drosten C. Hosts and Sources of Endemic Human Coronaviruses. Adv Virus Res. 2018;100:163-188. doi: 10.1016/bs.aivir.2018.01.001 pmid: 29551135

8. Smith RD. Responding to global infectious disease outbreaks: lessons from SARS on the role of risk perception, communication and management. Soc Sci Med. 2006;63(12):3113-3123. doi: 10.1016/j.socscimed.2006.08.004 pmid: 16978751 
9. Hall AJ, Tokars JI, Badreddine SA, Saad ZB, Furukawa E, Al Masri M, et al. Health care worker contact with MERS patient, Saudi Arabia. Emerg Infect Dis. 2014;20(12):2148-2151. doi: 10.3201/eid2012.141211 pmid: 25418612

10.Lu L, Liu Q, Du L, Jiang S. Middle East respiratory syndrome coronavirus (MERS-CoV): challenges in identifying its source and controlling its spread. Microbes Infect. 2013;15(8-9):625-629. doi: 10.1016/j.micinf.2013.06.003 pmid: 23791956

11.Zumla A, Chan JF, Azhar EI, Hui DS, Yuen KY. Coronaviruses - drug discovery and therapeutic options. Nat Rev Drug Discov. 2016;15(5):327-347. doi: 10.1038/nrd.2015.37 pmid: 26868298

12. Morse JS, Lalonde T, Xu S, Liu WR. Learning from the Past: Possible Urgent Prevention and Treatment Options for Severe Acute Respiratory Infections Caused by 2019-nCoV. Chembiochem. 2020;21(5):730738. doi: 10.1002/cbic. 202000047 pmid: 32022370

13. Cohen J. Wuhan seafood market may not be source of novel virus spreading globally. Science. 2020;10.

14. Chen N, Zhou M, Dong X, Qu J, Gong F, Han Y, et al. Epidemiological and clinical characteristics of 99 cases of 2019 novel coronavirus pneumonia in Wuhan, China: a descriptive study. Lancet. 2020;395(10223):507-513. doi: 10.1016/S0140-6736(20)30211-7 pmid: 32007143

15.Hessen M. Novel Coronavirus Information Center: Expert Guidance and Commentary: Elsevier Connect; 2020.

16. World Health Organization. Report of the WHO-China Joint Mission on Coronavirus Disease 2019 (COVID-19). Organization WHO; 2020 February.

17. Moxley G, Posthuma D, Carlson P, Estrada E, Han J, Benson LL, et al. Sexual dimorphism in innate immunity. Arthritis Rheum. 2002;46(1):250-258. doi: 10.1002/1529-0131(200201)46:1<250::AIDART10064>3.0.CO;2-T pmid: 11817599

18.Zhou Y, Fu B, Zheng X, Wang D, Zhao C. Pathogenic T cells and inflammatory monocytes incite inflammatory storm in severe COVID-19 patients. Natl Sci Rev. 2020;12(1). doi: 10.1093/nsr/nwaa041

19. Weyh C, Kruger K, Strasser B. Physical Activity and Diet Shape the Immune System during Aging. Nutrients. 2020;12(3):622. doi: 10.3390/nu12030622 pmid: 32121049

20. Kerr J, Anderson C, Lippman SM. Physical activity, sedentary behaviour, diet, and cancer: an update and emerging new evidence. Lancet Oncol. 2017;18(8):e457-e471. doi: 10.1016/S1470-2045(17)304114 pmid: 28759385

21.Kawai T, Akira S. The role of pattern-recognition receptors in innate immunity: update on Toll-like receptors. Nat Immunol. 2010;11(5):373-384. doi: 10.1038/ni.1863 pmid: 20404851

22. Cecere TE, Todd SM, Leroith T. Regulatory T cells in arterivirus and coronavirus infections: do they protect against disease or enhance it? Viruses. 2012;4(5):833-846. doi: 10.3390/v4050833 pmid: 22754651

23. Maloir Q, Ghysen K, von Frenckell C, Louis R, Guiot J. [Acute respiratory distress revealing antisynthetase syndrome]. Rev Med Liege. 2018;73(7-8):370-375. pmid: 30113776

24.Wu J, Zha P. Treatment Strategies for Reducing Damages to Lungs In Patients with Coronavirus and Other Infections. Available at SSRN 3533279. 2020.

25.Letko M, Marzi A, Munster V. Functional assessment of cell entry and receptor usage for SARS-CoV2 and other lineage B betacoronaviruses. Nat Microbiol. 2020;5(4):562-569. doi: 10.1038/s41564-0200688-y pmid: 32094589

26.Iwata-Yoshikawa N, Okamura T, Shimizu Y, Hasegawa H, Takeda M, Nagata N. TMPRSS2 Contributes to Virus Spread and Immunopathology in the Airways of Murine Models after Coronavirus Infection. $J$ Virol. 2019;93(6):e01815-01818. doi: 10.1128/JVI.01815-18 pmid: 30626688

27.Zhou Y, Vedantham P, Lu K, Agudelo J, Carrion R, Jr., Nunneley JW, et al. Protease inhibitors targeting coronavirus and filovirus entry. Antiviral Res. 2015;116:76-84. doi: 10.1016/j.antiviral.2015.01.011 pmid: 25666761

28. Gurwitz D. Angiotensin receptor blockers as tentative SARS-CoV-2 therapeutics. Drug Dev Res. 2020;81(5):537-540. doi: 10.1002/ddr.21656 pmid: 32129518

29.Liu WJ, Zhao M, Liu K, Xu K, Wong G, Tan W, et al. T-cell immunity of SARS-CoV: Implications for vaccine development against MERS-CoV. Antiviral Res. 2017;137:82-92. doi: 10.1016/j.antiviral.2016.11.006 pmid: 27840203 
30. Nieman DC, Wentz LM. The compelling link between physical activity and the body's defense system. J Sport Health Sci. 2019;8(3):201-217. doi: 10.1016/j.jshs.2018.09.009 pmid: 31193280

31. Gleeson M, Bishop NC, Stensel DJ, Lindley MR, Mastana SS, Nimmo MA. The anti-inflammatory effects of exercise: mechanisms and implications for the prevention and treatment of disease. Nat Rev Immunol. 2011;11(9):607-615. doi: 10.1038/nri3041 pmid: 21818123

32.Petersen AM, Pedersen BK. The anti-inflammatory effect of exercise. J Appl Physiol (1985). 2005;98(4):1154-1162. doi: 10.1152/japplphysiol.00164.2004 pmid: 15772055

33. Hamlin M, Draper N. Current Issues in Sports and Exercise Medicine: BoD-Books on Demand; 2013.

34. Terra R, Silva Sd, Pinto VS, Dutra P. Effect of exercise on the immune system: response, adaptation and cell signaling. Rev Bras Med Esporte. 2012;18(3):208-214.

35. Wang J, Song H, Tang X, Yang Y, Vieira VJ, Niu Y, et al. Effect of exercise training intensity on murine T-regulatory cells and vaccination response. Scand J Med Sci Sports. 2012;22(5):643-652. doi: 10.1111/j.1600-0838.2010.01288.x pmid: 21410542

36. Nieman DC. Exercise, infection, and immunity. Int J Sports Med. 1994;15 Suppl 3(S 3):S131-141. doi: 10.1055/s-2007-1021128 pmid: 7883395

37.Hennet T, Peterhans E, Stocker R. Alterations in antioxidant defences in lung and liver of mice infected with influenza A virus. J Gen Virol. 1992;73 ( Pt 1)(1):39-46. doi: 10.1099/0022-1317-73-1-39 pmid: 1530963

38. Shephard RJ, Shek PN. Potential impact of physical activity and sport on the immune system--a brief review. Br J Sports Med. 1994;28(4):247-255. doi: 10.1136/bjsm.28.4.247 pmid: 7894956

39. Simpson RJ, Kunz H, Agha N, Graff R. Exercise and the regulation of immune functions. Progress in molecular biology and translational science. 135: Elsevier; 2015. p. 355-380.

40. de Sousa CV, Sales MM, Rosa TS, Lewis JE, de Andrade RV, Simoes HG. The Antioxidant Effect of Exercise: A Systematic Review and Meta-Analysis. Sports Med. 2017;47(2):277-293. doi: 10.1007/s40279-016-0566-1 pmid: 27260682

41.Shimizu K, Kimura F, Akimoto T, Akama T, Tanabe K, Nishijima T, et al. Effect of moderate exercise training on T-helper cell subpopulations in elderly people. Exerc Immunol Rev. 2008;14(1):24-37. pmid: 19203082

42. Anderson E, Shivakumar G. Effects of exercise and physical activity on anxiety. Front Psychiatry. 2013;4:27. doi: 10.3389/fpsyt.2013.00027 pmid: 23630504

43.Lin TW, Kuo YM. Exercise benefits brain function: the monoamine connection. Brain Sci. 2013;3(1):3953. doi: 10.3390/brainsci3010039 pmid: 24961306

44. Sciolino NR, Holmes PV. Exercise offers anxiolytic potential: a role for stress and brain noradrenergicgalaninergic mechanisms. Neurosci Biobehav Rev. 2012;36(9):1965-1984. doi: 10.1016/j.neubiorev.2012.06.005 pmid: 22771334

45. Mo P, Xing Y, Xiao Y, Deng L, Zhao Q, Wang H, et al. Clinical characteristics of refractory COVID19 pneumonia in Wuhan, China. Clin Infect Dis. 2020. doi: 10.1093/cid/ciaa270 pmid: 32173725

46. Hu H, Ma F, Wei X, Fang Y. Coronavirus fulminant myocarditis treated with glucocorticoid and human immunoglobulin. Eur Heart J. 2021;42(2):206. doi: 10.1093/eurheartj/ehaa190 pmid: 32176300

47.Jin CH, Rhyu HS, Kim JY. The effects of combined aerobic and resistance training on inflammatory markers in obese men. J Exerc Rehabil. 2018;14(4):660-665. doi: 10.12965/jer.1836294.147 pmid: 30276190

48. Wedell-Neergaard AS, Krogh-Madsen R, Petersen GL, Hansen AM, Pedersen BK, Lund R, et al. Cardiorespiratory fitness and the metabolic syndrome: Roles of inflammation and abdominal obesity. PLoS One. 2018;13(3):e0194991. doi: 10.1371/journal.pone.0194991 pmid: 29590212

49.Flynn MG, McFarlin BK. Toll-like receptor 4: link to the anti-inflammatory effects of exercise? Exerc Sport Sci Rev. 2006;34(4):176-181. doi: 10.1249/01.jes.0000240027.22749.14 pmid: 17031256

50. Ouchi N, Parker JL, Lugus JJ, Walsh K. Adipokines in inflammation and metabolic disease. Nat Rev Immunol. 2011;11(2):85-97. doi: 10.1038/nri2921 pmid: 21252989

51.Esposito K, Pontillo A, Di Palo C, Giugliano G, Masella M, Marfella R, et al. Effect of weight loss and lifestyle changes on vascular inflammatory markers in obese women: a randomized trial. JAMA. 2003;289(14):1799-1804. doi: 10.1001/jama.289.14.1799 pmid: 12684358 
52. Kasapis C, Thompson PD. The effects of physical activity on serum C-reactive protein and inflammatory markers: a systematic review. $J$ Am Coll Cardiol. 2005;45(10):1563-1569. doi: 10.1016/j.jacc.2004.12.077 pmid: 15893167

53. Fitch KD. An overview of asthma and airway hyper-responsiveness in Olympic athletes. Br J Sports Med. 2012;46(6):413-416. doi: 10.1136/bjsports-2011-090814 pmid: 22228581

54.Pedersen BK, Fischer CP. Beneficial health effects of exercise--the role of IL-6 as a myokine. Trends Pharmacol Sci. 2007;28(4):152-156. doi: 10.1016/j.tips.2007.02.002 pmid: 17331593

55.McCarthy DA, Dale MM. The leucocytosis of exercise. A review and model. Sports Med. 1988;6(6):333363. doi: 10.2165/00007256-198806060-00002 pmid: 3068772

56. Wolach B, Falk B, Gavrieli R, Kodesh E, Eliakim A. Neutrophil function response to aerobic and anaerobic exercise in female judoka and untrained subjects. Br J Sports Med. 2000;34(1):23-28. doi: 10.1136/bjsm.34.1.23 pmid: 10690446

57.Brolinson PG, Elliott D. Exercise and the immune system. Clin Sports Med. 2007;26(3):311-319. doi: 10.1016/j.csm.2007.04.011 pmid: 17826186

58. Klentrou P, Cieslak T, MacNeil M, Vintinner A, Plyley M. Effect of moderate exercise on salivary immunoglobulin A and infection risk in humans. Eur J Appl Physiol. 2002;87(2):153-158. doi: 10.1007/s00421-002-0609-1 pmid: 12070626

59. Nunes-Silva A, Rocha GC, Magalhaes DM, Vaz LN, Salviano de Faria MH, Simoes ESAC. Physical Exercise and ACE2-Angiotensin-(1-7)-Mas Receptor Axis of the Renin Angiotensin System. Protein Pept Lett. 2017;24(9):809-816. doi: 10.2174/0929866524666170728151401 pmid: 28758593

60. Magalhaes DM, Nunes-Silva A, Rocha GC, Vaz LN, de Faria MHS, Vieira ELM, et al. Two protocols of aerobic exercise modulate the counter-regulatory axis of the renin-angiotensin system. Heliyon. 2020;6(1):e03208. doi: 10.1016/j.heliyon.2020.e03208 pmid: 31989052

61.Prata LO, Rodrigues CR, Martins JM, Vasconcelos PC, Oliveira FM, Ferreira AJ, et al. Original Research: ACE2 activator associated with physical exercise potentiates the reduction of pulmonary fibrosis. Exp Biol Med (Maywood). 2017;242(1):8-21. doi: 10.1177/1535370216665174 pmid: 27550926

62. Heijnen S, Hommel B, Kibele A, Colzato LS. Neuromodulation of Aerobic Exercise-A Review. Front Psychol. 2015;6:1890. doi: 10.3389/fpsyg.2015.01890 pmid: 26779053

63. Wang C, Pan R, Wan X, Tan Y, Xu L, Ho CS, et al. Immediate Psychological Responses and Associated Factors during the Initial Stage of the 2019 Coronavirus Disease (COVID-19) Epidemic among the General Population in China. Int $J$ Environ Res Public Health. 2020;17(5):1729. doi: 10.3390/ijerph17051729 pmid: 32155789

64. Meeusen R, De Meirleir K. Exercise and brain neurotransmission. Sports Med. 1995;20(3):160-188. doi: 10.2165/00007256-199520030-00004 pmid: 8571000

65. Rimmele U, Zellweger BC, Marti B, Seiler R, Mohiyeddini C, Ehlert U, et al. Trained men show lower cortisol, heart rate and psychological responses to psychosocial stress compared with untrained men. Psychoneuroendocrinology. 2007;32(6):627-635. doi: 10.1016/j.psyneuen.2007.04.005 pmid: 17560731

66. Schwarz KB. Oxidative stress during viral infection: a review. Free Radic Biol Med. 1996;21(5):641649. doi: 10.1016/0891-5849(96)00131-1 pmid: 8891667

67.Zheng YY, Ma YT, Zhang JY, Xie X. COVID-19 and the cardiovascular system. Nat Rev Cardiol. 2020;17(5):259-260. doi: 10.1038/s41569-020-0360-5 pmid: 32139904

68.Pepe H, Balci SS, Revan S, Akalin PP, Kurtoglu F. Comparison of oxidative stress and antioxidant capacity before and after running exercises in both sexes. Gend Med. 2009;6(4):587-595. doi: 10.1016/j.genm.2009.10.001 pmid: 20114009

69. Ghiasi R, Mohammadi M, Ashrafi Helan J, Jafari Jozani SR, Mohammadi S, Ghiasi A, et al. Influence of Two Various Durations of Resistance Exercise on Oxidative Stress in the Male Rat's Hearts. $J$ Cardiovasc Thorac Res. 2015;7(4):149-153. doi: 10.15171/jcvtr.2015.32 pmid: 26702343

70. Sun P, Lu X, Xu C, Sun W, Pan B. Understanding of COVID-19 based on current evidence. J Med Virol. 2020;92(6):548-551. doi: 10.1002/jmv.25722 pmid: 32096567 
71. Kahkhaie KR, Mirhosseini A, Aliabadi A, Mohammadi A, Mousavi MJ, Haftcheshmeh SM, et al. Curcumin: a modulator of inflammatory signaling pathways in the immune system. Inflammopharmacology. 2019;27(5):885-900. doi: 10.1007/s10787-019-00607-3 pmid: 31140036

72. Authority EFS. Refined exposure assessment for curcumin (E 100). EFSA Journal. 2014;12(10):3876.

73. McFarlin BK, Venable AS, Henning AL, Sampson JN, Pennel K, Vingren JL, et al. Reduced inflammatory and muscle damage biomarkers following oral supplementation with bioavailable curcumin. BBA Clin. 2016;5:72-78. doi: 10.1016/j.bbacli.2016.02.003 pmid: 27051592

74. Shen L, Liu CC, An CY, Ji HF. How does curcumin work with poor bioavailability? Clues from experimental and theoretical studies. Sci Rep. 2016;6(1):20872. doi: 10.1038/srep20872 pmid: 26887346

75.Xu Y, Liu L. Curcumin alleviates macrophage activation and lung inflammation induced by influenza virus infection through inhibiting the NF-kappaB signaling pathway. Influenza Other Respir Viruses. 2017;11(5):457-463. doi: 10.1111/irv.12459 pmid: 28646616

76. Haque S, Lee H, Waqas B, Chiorazzi N, Mongini P. Anti-inflammatory curcumin inhibits AID expression within cycling human B cells (96.21): Am Assoc Immnol; 2010.

77. Boroumand N, Samarghandian S, Hashemy SI. Immunomodulatory, anti-inflammatory, and antioxidant effects of curcumin. J Herbmed Pharmacol. 2018;7(4).

78. Abdollahi E, Momtazi AA, Johnston TP, Sahebkar A. Therapeutic effects of curcumin in inflammatory and immune-mediated diseases: A nature-made jack-of-all-trades? J Cell Physiol. 2018;233(2):830-848. doi: $10.1002 /$ jcp. 25778 pmid: 28059453

79. Avasarala S, Zhang F, Liu G, Wang R, London SD, London L. Curcumin modulates the inflammatory response and inhibits subsequent fibrosis in a mouse model of viral-induced acute respiratory distress syndrome. PLoS One. 2013;8(2):e57285. doi: 10.1371/journal.pone.0057285 pmid: 23437361

80. Avasarala S, Zhang F, Liu G, Wang R, London SD, London L. Correction: Curcumin Modulates the Inflammatory Response and Inhibits Subsequent Fibrosis in a Mouse Model of Viral-induced Acute Respiratory Distress Syndrome. PLoS One. 2015;10(8):e0134982. doi: 10.1371/journal.pone.0134982 pmid: 26241041

81. Rathore S, Mukim M, Sharma P, Devi S, Nagar JC, Khalid M. Curcumin: A Review for Health Benefits. Int J Res Rev. 2020;7(1):273-290.

82. Sciberras JN, Galloway SD, Fenech A, Grech G, Farrugia C, Duca D, et al. The effect of turmeric (Curcumin) supplementation on cytokine and inflammatory marker responses following 2 hours of endurance cycling. J Int Soc Sports Nutr. 2015;12(1):5. doi: 10.1186/s12970-014-0066-3 pmid: 25628521

83. Samarghandian S, Azimi-Nezhad M, Farkhondeh T, Samini F. Anti-oxidative effects of curcumin on immobilization-induced oxidative stress in rat brain, liver and kidney. Biomed Pharmacother. 2017;87:223-229. doi: 10.1016/j.biopha.2016.12.105 pmid: 28061405

84. Gali-Muhtasib H, El-Najjar N, Schneider-Stock R. The medicinal potential of black seed (Nigella sativa) and its components. Adv Phytomed. 2006;2(1):133-153.

85. Woo CC, Kumar AP, Sethi G, Tan KH. Thymoquinone: potential cure for inflammatory disorders and cancer. Biochem Pharmacol. 2012;83(4):443-451. doi: 10.1016/j.bcp.2011.09.029 pmid: 22005518

86. Ali BH, Blunden G. Pharmacological and toxicological properties of Nigella sativa. Phytother Res. 2003;17(4):299-305. doi: 10.1002/ptr.1309 pmid: 12722128

87. Mansour M, Tornhamre S. Inhibition of 5-lipoxygenase and leukotriene C4 synthase in human blood cells by thymoquinone. $J$ Enzyme Inhib Med Chem. 2004;19(5):431-436. doi: 10.1080/14756360400002072 pmid: 15648658

88. Kalus U, Pruss A, Bystron J, Jurecka M, Smekalova A, Lichius JJ, et al. Effect of Nigella sativa (black seed) on subjective feeling in patients with allergic diseases. Phytother Res. 2003;17(10):1209-1214. doi: 10.1002/ptr.1356 pmid: 14669258

89. Gilani A-uH, Jabeen Q, Khan MAU. A review of medicinal uses and pharmacological activities of Nigella sativa. Pak J Biol Sci. 2004;7(4):441-451.

90. Boskabady MH, Vahedi N, Amery S, Khakzad MR. The effect of Nigella sativa alone, and in combination with dexamethasone, on tracheal muscle responsiveness and lung inflammation in sulfur 
mustard exposed guinea pigs. $J$ Ethnopharmacol. 2011;137(2):1028-1034. doi: 10.1016/j.jep.2011.07.030 pmid: 21801826

91.Khan MA. Chemical composition and medicinal properties of Nigella sativa Linn. Inflammopharmacology. 1999;7(1):15-35. doi: 10.1007/s10787-999-0023-y pmid: 17657444

92. Raza Asim MB, Shahzad M, Yang X, Sun Q, Zhang F, Han Y, et al. Suppressive effects of black seed oil on ovalbumin induced acute lung remodeling in E3 rats. Swiss Med Wkly. 2010;140(4950):w13128. doi: 10.4414/smw.2010.13128 pmid: 21136334

93. Mokhtari-Zaer A, Norouzi F, Askari VR, Khazdair MR, Roshan NM, Boskabady M, et al. The protective effect of Nigella sativa extract on lung inflammation and oxidative stress induced by lipopolysaccharide in rats. J Ethnopharmacol. 2020;253:112653. doi: 10.1016/j.jep.2020.112653 pmid: 32035219

94. Ranjan V, Vats M, Gupta N, Sardana S. Antidiabetic potential of whole plant of Adiantum capillus veneris linn. in streptozotocin induced diabetic rats. IJPCR. 2014;6(4):341-347.

95. Yadegari M, Riahy S, Mirdar S, Hamidian G, Afkhami SM, Saeidi A, et al. The TNF-alpha, P53 protein response and lung respiratory changes to exercise, chronic hypoxia and Adiantum capillus-veneris supplementation. Adv Respir Med. 2019;87(4):226-234. doi: 10.5603/ARM.2019.0037 pmid: 31476010

96. Marino A, Elberti MG, Cataldo A. [Phytochemical investigation of Adiantum capillus veneris]. Boll Soc Ital Biol Sper. 1989;65(5):461-463. pmid: 2775551

97. Yuan Q, Zhang X, Liu Z, Song S, Xue P, Wang J, et al. Ethanol extract of Adiantum capillus-veneris L. suppresses the production of inflammatory mediators by inhibiting NF-kappaB activation. $J$ Ethnopharmacol. 2013;147(3):603-611. doi: 10.1016/j.jep.2013.03.046 pmid: 23542147

98. Kumar A. Antioxidant Effect of Adiantum Capillus Veneris Linn. on human lymphocyte: an in vitro study. J Cell Tissue Res. 2009;9(2):1899.

99.Letchamo W, Gosselin A. Transpiration, essential oil glands, epicuticular wax and morphology of Thymus vulgaris are influenced by light intensity and water supply. J Horticult Sci. 1996;71(1):123-134.

100. Amirghofran Z, Hashemzadeh R, Javidnia K, Golmoghaddam H, Esmaeilbeig A. In vitro immunomodulatory effects of extracts from three plants of the Labiatae family and isolation of the active compound(s). J Immunotoxicol. 2011;8(4):265-273. doi: 10.3109/1547691X.2011.590828 pmid: 21711089

101. Keefover-Ring K, Thompson JD, Linhart YB. Beyond six scents: defining a seventh Thymus vulgaris chemotype new to southern France by ethanol extraction. Flavour Fragrance J. 2009;24(3):117122.

102. Alonso JR. Tratado de fitomedicina: bases clínicas y farmacológicas: Isis Ediciones; 1998.

103. Soliman KM, Badeaa RI. Effect of oil extracted from some medicinal plants on different mycotoxigenic fungi. Food Chem Toxicol. 2002;40(11):1669-1675. doi: 10.1016/s02786915(02)00120-5 pmid: 12176092

104. Bukovska A, Cikos S, Juhas S, Il'kova G, Rehak P, Koppel J. Effects of a combination of thyme and oregano essential oils on TNBS-induced colitis in mice. Mediators Inflamm. 2007;2007:23296. doi: 10.1155/2007/23296 pmid: 18288268

105. Van Den Broucke CO, Lemli JA. Spasmolytic activity of the flavonoids from Thymus vulgaris. Pharm Weekbl Sci. 1983;5(1):9-14. doi: 10.1007/BF01959645 pmid: 6844124

106. Vigo E, Cepeda A, Gualillo O, Perez-Fernandez R. In-vitro anti-inflammatory effect of Eucalyptus globulus and Thymus vulgaris: nitric oxide inhibition in J774A.1 murine macrophages. J Pharm Pharmacol. 2004;56(2):257-263. doi: 10.1211/0022357022665 pmid: 15005885

107. Hudaib M, Speroni E, Di Pietra AM, Cavrini V. GC/MS evaluation of thyme (Thymus vulgaris L.) oil composition and variations during the vegetative cycle. J Pharm Biomed Anal. 2002;29(4):691-700. doi: 10.1016/s0731-7085(02)00119-x pmid: 12093498

108. Tian H, Lai DM. [Analysis on the volatile oil in Origanum vulgare]. Zhong Yao Cai. 2006;29(9):920-921. pmid: 17212048

109. Braga PC, Dal Sasso M, Culici M, Bianchi T, Bordoni L, Marabini L. Anti-inflammatory activity of thymol: inhibitory effect on the release of human neutrophil elastase. Pharmacology. 2006;77(3):130136. doi: $10.1159 / 000093790$ pmid: 16763380

110. Suzuki Y, Furuta H. Stimulation of guinea pig neutrophil superoxide anion-producing system with thymol. Inflammation. 1988;12(6):575-584. doi: 10.1007/BF00914319 pmid: 2851551 
111. Aeschbach R, Loliger J, Scott BC, Murcia A, Butler J, Halliwell B, et al. Antioxidant actions of thymol, carvacrol, 6-gingerol, zingerone and hydroxytyrosol. Food Chem Toxicol. 1994;32(1):31-36. doi: 10.1016/0278-6915(84)90033-4 pmid: 7510659

112. Segvic Klaric M, Kosalec I, Mastelic J, Pieckova E, Pepeljnak S. Antifungal activity of thyme (Thymus vulgaris L.) essential oil and thymol against moulds from damp dwellings. Lett Appl Microbiol. 2007;44(1):36-42. doi: 10.1111/j.1472-765X.2006.02032.x pmid: 17209812

113. Fujisawa S, Kadoma Y. Effect of phenolic compounds on the polymerization of methyl methacrylate. Dent Mater. 1992;8(5):324-326. doi: 10.1016/0109-5641(92)90108-o pmid: 1303375

114. Bozin B, Mimica-Dukic N, Samojlik I, Jovin E. Antimicrobial and antioxidant properties of rosemary and sage (Rosmarinus officinalis L. and Salvia officinalis L., Lamiaceae) essential oils. J Agric Food Chem. 2007;55(19):7879-7885. doi: 10.1021/jf0715323 pmid: 17708648

115. Horosova K, Bujnakova D, Kmet V. Effect of oregano essential oil on chicken lactobacilli and E. coli. Folia Microbiol (Praha). 2006;51(4):278-280. doi: 10.1007/BF02931812 pmid: 17007424

116. Alma MH, Mavi A, Yildirim A, Digrak M, Hirata T. Screening chemical composition and in vitro antioxidant and antimicrobial activities of the essential oils from Origanum syriacum L. growing in Turkey. Biol Pharm Bull. 2003;26(12):1725-1729. doi: 10.1248/bpb.26.1725 pmid: 14646179

117. Arcila-Lozano CC, Loarca-Pina G, Lecona-Uribe S, Gonzalez de Mejia E. [Oregano: properties, composition and biological activity]. Arch Latinoam Nutr. 2004;54(1):100-111. pmid: 15332363

118. Juhas S, Cikos S, Czikkova S, Vesela J, Il'kova G, Hajek T, et al. Effects of borneol and thymoquinone on TNBS-induced colitis in mice. Folia Biol (Praha). 2008;54(1):1-7. pmid: 18226358

119. Ocana A, Reglero G. Effects of Thyme Extract Oils (from Thymus vulgaris, Thymus zygis, and Thymus hyemalis) on Cytokine Production and Gene Expression of oxLDL-Stimulated THP-1Macrophages. J Obes. 2012;2012:104706. doi: 10.1155/2012/104706 pmid: 22577523

120. Kim SK, Kim HJ, Choi SE, Park KH, Choi HK, Lee MW. Anti-oxidative and inhibitory activities on nitric oxide (NO) and prostaglandin E2 (COX-2) production of flavonoids from seeds of Prunus tomentosa Thunberg. Arch Pharm Res. 2008;31(4):424-428. doi: 10.1007/s12272-001-1174-9 pmid: 18449498

121. Berg J, Fellier H, Christoph T, Grarup J, Stimmeder D. The analgesic NSAID lornoxicam inhibits cyclooxygenase (COX)-1/-2, inducible nitric oxide synthase (iNOS), and the formation of interleukin

(IL)-6 in vitro. Inflamm Res. 1999;48(7):369-379. doi: 10.1007/s000110050474 pmid: 10450786

122. Juhás Š, Bujňáková D, Rehák P, Čikoš Š, Czikková S, Veselá J, et al. Anti-inflammatory effects of thyme essential oil in mice. Acta Veterinaria Brno. 2008;77(3):327-334.

123. Ikeda U, Ikeda M, Seino Y, Takahashi M, Kano S, Shimada K. Interleukin 6 gene transcripts are expressed in atherosclerotic lesions of genetically hyperlipidemic rabbits. Atherosclerosis. 1992;92(23):213-218. doi: 10.1016/0021-9150(92)90280-t pmid: 1632849

124. Uyemura K, Demer LL, Castle SC, Jullien D, Berliner JA, Gately MK, et al. Cross-regulatory roles of interleukin (IL)-12 and IL-10 in atherosclerosis. J Clin Invest. 1996;97(9):2130-2138. doi: 10.1172/JCI118650 pmid: 8621803

125. Arend WP, Gabay C. Cytokines in the rheumatic diseases. Rheum Dis Clin North Am. 2004;30(1):41-67, v-vi. doi: 10.1016/S0889-857X(03)00115-7 pmid: 15061568

126. Feghali CA, Wright TM. Cytokines in acute and chronic inflammation. Front Biosci. 1997;2(1):d12-26. doi: 10.2741/a171 pmid: 9159205

127. Chao LK, Hua KF, Hsu HY, Cheng SS, Liu JY, Chang ST. Study on the antiinflammatory activity of essential oil from leaves of Cinnamomum osmophloeum. J Agric Food Chem. 2005;53(18):72747278. doi: 10.1021/jf051151u pmid: 16131142

128. Ozgoli G, Goli M, Moattar F. Comparison of effects of ginger, mefenamic acid, and ibuprofen on pain in women with primary dysmenorrhea. J Altern Complement Med. 2009;15(2):129-132. doi: 10.1089/acm.2008.0311 pmid: 19216660

129. Masuda Y, Kikuzaki H, Hisamoto M, Nakatani N. Antioxidant properties of gingerol related compounds from ginger. Biofactors. 2004;21(1-4):293-296. doi: 10.1002/biof.552210157 pmid: 15630214

130. Egwurugwu J, Ufearo C, Abanobi O, Nwokocha C, Duruibe J, Adeleye G, et al. Effects of ginger (Zingiber officinale) on cadmium toxicity. Africa J Biotech. 2007;6(18). 
131. Levy AS, Simon O, Shelly J, Gardener M. 6-Shogaol reduced chronic inflammatory response in the knees of rats treated with complete Freund's adjuvant. BMC Pharmacol. 2006;6(1):12. doi: 10.1186/1471-2210-6-12 pmid: 17010215

132. Manju V, Nalini N. Chemopreventive efficacy of ginger, a naturally occurring anticarcinogen during the initiation, post-initiation stages of 1,2 dimethylhydrazine-induced colon cancer. Clin Chim Acta. 2005;358(1-2):60-67. doi: 10.1016/j.cccn.2005.02.018 pmid: 16018877

133. Grzanna R, Lindmark L, Frondoza CG. Ginger--an herbal medicinal product with broad antiinflammatory actions. J Med Food. 2005;8(2):125-132. doi: 10.1089/jmf.2005.8.125 pmid: 16117603

134. Haghighi M, Khalvat A, Toliat T, Jallaei S. Comparing the effects of ginger (Zingiber officinale) extract and ibuprofen on patients with osteoarthritis. Arch Iran Med. 2005;8(4):267-271.

135. Tripathi S, Bruch D, Kittur DS. Ginger extract inhibits LPS induced macrophage activation and function. BMC Complement Altern Med. 2008;8(1):1. doi: 10.1186/1472-6882-8-1 pmid: 18173849

136. Akhavan Amjadi M, Mojab F, Shagbazzadegan S. Efficacy of cinnamomum zeylanicum on primary dysmenorrhea and systemic symptom of it on the students of Gilan university of medical sciences 2007. J Ardabil Uni Med Sci. 2009;9(3):204-209.

137. Angmor J, Dicks D, Evans W, Santra D. Studies on Cinnamomun Zeylanicum-Part I. The Essential Oil Components of C. zeylanicum Nees Grown in Ghana. Planta Medica. 1972;21(04):416-420.

138. Shah AH, Al-Shareef AH, Ageel AM, Qureshi S. Toxicity studies in mice of common spices, Cinnamomum zeylanicum bark and Piper longum fruits. Plant Foods Hum Nutr. 1998;52(3):231-239. doi: 10.1023/a:1008088323164 pmid: 9950084

139. Mohammad Beigi N, Haghighi Asl A. Hormozi, f. 2008. Investigation of various factors Drasansgyry of cinnamon. College Engin. 2008;42(2):199-203.

140. Kamali RL, Ghavami M, Elhami Rad A, Azizinezhad R. Evaluation of the Antioxidant and Chelating Activities of Cinnamon Extract. J Food Tech Nutrition. 2014;11(2):37-46.

141. Ose R, Tu J, Schink A, Maxeiner J, Schuster P, Lucas K, et al. Cinnamon extract inhibits allergenspecific immune responses in human and murine allergy models. Clin Exp Allergy. 2020;50(1):41-50. doi: 10.1111/cea.13507 pmid: 31573731

142. Wu D, Lewis ED, Pae M, Meydani SN. Nutritional Modulation of Immune Function: Analysis of Evidence, Mechanisms, and Clinical Relevance. Front Immunol. 2018;9:3160. doi: 10.3389/fimmu.2018.03160 pmid: 30697214

143. Walker CLF, Rudan I, Liu L, Nair H, Theodoratou E, Bhutta ZA, et al. Global burden of childhood pneumonia and diarrhoea. Lancet. 2013;381(9875):1405-1416. doi: 10.1016/S0140-6736(13)60222-6 pmid: 23582727

144. Andreini C, Banci L, Bertini I, Rosato A. Counting the zinc-proteins encoded in the human genome. J Proteome Res. 2006;5(1):196-201. doi: 10.1021/pr050361j pmid: 16396512

145. Maywald M, Wessels I, Rink L. Zinc Signals and Immunity. Int J Mol Sci. 2017;18(10):2222. doi: 10.3390/ijms18102222 pmid: 29064429

146. Wan Y, Petris MJ, Peck SC. Separation of zinc-dependent and zinc-independent events during early LPS-stimulated TLR4 signaling in macrophage cells. FEBS Lett. 2014;588(17):2928-2935. doi: 10.1016/j.febslet.2014.05.043 pmid: 24911202

147. King LE, Frentzel JW, Mann JJ, Fraker PJ. Chronic zinc deficiency in mice disrupted T cell lymphopoiesis and erythropoiesis while B cell lymphopoiesis and myelopoiesis were maintained. $J$ Am Coll Nutr. 2005;24(6):494-502. doi: 10.1080/07315724.2005.10719495 pmid: 16373946

148. Honscheid A, Rink L, Haase H. T-lymphocytes: a target for stimulatory and inhibitory effects of zinc ions. Endocr Metab Immune Disord Drug Targets. 2009;9(2):132-144. doi: 10.2174/187153009788452390 pmid: 19519463

149. Beck FW, Prasad AS, Kaplan J, Fitzgerald JT, Brewer GJ. Changes in cytokine production and T cell subpopulations in experimentally induced zinc-deficient humans. Am J Physiol. 1997;272(6 Pt 1):E1002-1007. doi: 10.1152/ajpendo.1997.272.6.E1002 pmid: 9227444

150. Rosenkranz E, Hilgers RD, Uciechowski P, Petersen A, Plumakers B, Rink L. Zinc enhances the number of regulatory $\mathrm{T}$ cells in allergen-stimulated cells from atopic subjects. Eur $J$ Nutr. 2017;56(2):557-567. doi: 10.1007/s00394-015-1100-1 pmid: 26589301 
151. Gammoh NZ, Rink L. Zinc in Infection and Inflammation. Nutrients. 2017;9(6):624. doi: 10.3390/nu9060624 pmid: 28629136

152. Kewcharoenwong C, Schuster GU, Wessells KR, Hinnouho GM, Barffour MA, Kounnavong S, et al. Daily Preventive Zinc Supplementation Decreases Lymphocyte and Eosinophil Concentrations in Rural Laotian Children from Communities with a High Prevalence of Zinc Deficiency: Results of a Randomized Controlled Trial. J Nutr. 2020;150(8):2204-2213. doi: 10.1093/jn/nxaa037 pmid: 32119742

153. Burns JJ. Missing step in man, monkey and guinea pig required for the biosynthesis of L-ascorbic acid. Nature. 1957;180(4585):553. doi: 10.1038/180553a0 pmid: 13477232

154. Nishikimi M, Fukuyama R, Minoshima S, Shimizu N, Yagi K. Cloning and chromosomal mapping of the human nonfunctional gene for L-gulono-gamma-lactone oxidase, the enzyme for L-ascorbic acid biosynthesis missing in man. J Biol Chem. 1994;269(18):13685-13688. pmid: 8175804

155. Burri B, Jacob R, Packer L, Fuchs J. Human metabolism and the requirement for vitamin C. Vitamin C Health Disease. 1997;2(1):341-366.

156. Hemila H. Vitamin C and Infections. Nutrients. 2017;9(4):339. doi: 10.3390/nu9040339 pmid: 28353648

157. Carr AC, McCall C. The role of vitamin C in the treatment of pain: new insights. J Transl Med. 2017;15(1):77. doi: 10.1186/s12967-017-1179-7 pmid: 28410599

158. Krebs H. The Sheffield experiment on the vitamin C requirement of human adults. Proceed Nut Soc. 1953;12(3):237-246.

159. Monsen ER. Dietary reference intakes for the antioxidant nutrients: vitamin C, vitamin E, selenium, and carotenoids. $J$ Am Diet Assoc. 2000;100(6):637-640. doi: 10.1016/S0002-8223(00)00189-9 pmid: 10863565

160. Carr A, Frei B. Does vitamin C act as a pro-oxidant under physiological conditions? FASEB J. 1999;13(9):1007-1024. doi: 10.1096/fasebj.13.9.1007 pmid: 10336883

161. Mandl J, Szarka A, Banhegyi G. Vitamin C: update on physiology and pharmacology. $\mathrm{Br} J$ Pharmacol. 2009;157(7):1097-1110. doi: 10.1111/j.1476-5381.2009.00282.x pmid: 19508394

162. Sharma P, Raghavan SA, Saini R, Dikshit M. Ascorbate-mediated enhancement of reactive oxygen species generation from polymorphonuclear leukocytes: modulatory effect of nitric oxide. J Leukoc Biol. 2004;75(6):1070-1078. doi: 10.1189/jlb.0903415 pmid: 15039465

163. Fisher BJ, Kraskauskas D, Martin EJ, Farkas D, Wegelin JA, Brophy D, et al. Mechanisms of attenuation of abdominal sepsis induced acute lung injury by ascorbic acid. Am J Physiol Lung Cell Mol Physiol. 2012;303(1):L20-32. doi: 10.1152/ajplung.00300.2011 pmid: 22523283

164. Molina N, Morandi AC, Bolin AP, Otton R. Comparative effect of fucoxanthin and vitamin C on oxidative and functional parameters of human lymphocytes. Int Immunopharmacol. 2014;22(1):41-50. doi: 10.1016/j.intimp.2014.06.026 pmid: 24975831

165. Hagel AF, Layritz CM, Hagel WH, Hagel HJ, Hagel E, Dauth W, et al. Intravenous infusion of ascorbic acid decreases serum histamine concentrations in patients with allergic and non-allergic diseases. Naunyn Schmiedebergs Arch Pharmacol. 2013;386(9):789-793. doi: 10.1007/s00210-0130880-1 pmid: 23666445

166. Carr AC, Maggini S. Vitamin C and Immune Function. Nutrients. 2017;9(11):1211. doi: 10.3390/nu9111211 pmid: 29099763

167. Erol A. High-dose intravenous vitamin C treatment for COVID-19. Istanbul, Turkey2020.

168. Arreola R, Quintero-Fabian S, Lopez-Roa RI, Flores-Gutierrez EO, Reyes-Grajeda JP, CarreraQuintanar L, et al. Immunomodulation and anti-inflammatory effects of garlic compounds. J Immunol Res. 2015;2015:401630. doi: 10.1155/2015/401630 pmid: 25961060

169. Clement F, Pramod SN, Venkatesh YP. Identity of the immunomodulatory proteins from garlic (Allium sativum) with the major garlic lectins or agglutinins. Int Immunopharmacol. 2010;10(3):316324. doi: 10.1016/j.intimp.2009.12.002 pmid: 20004743

170. Mehrbod P, Amini E, Tavassoti-Kheiri M. Antiviral activity of garlic extract on influenza virus. Iran J Virol. 2009;3(1):19-23. 
171. Song H, Lu Y, Qu Z, Mossine VV, Martin MB, Hou J, et al. Effects of aged garlic extract and FruArg on gene expression and signaling pathways in lipopolysaccharide-activated microglial cells. Sci Rep. 2016;6:35323. doi: 10.1038/srep35323 pmid: 27734935

172. Bogdanov S. Quality and standards of pollen and beeswax. Apiacta. 2004;38(11):334-341.

173. Olczyk P, Wisowski G, Komosinska-Vassev K, Stojko J, Klimek K, Olczyk M, et al. Propolis Modifies Collagen Types I and III Accumulation in the Matrix of Burnt Tissue. Evid Based Complement Alternat Med. 2013;2013:423809. doi: 10.1155/2013/423809 pmid: 23781260

174. Eshraghi S, Valafar S. Evaluation of inhibitory effects of Iranian propolis against filamentous bacteria. Pakistan J Med Sci. 2008;24(1):56.

175. Bachiega TF, Orsatti CL, Pagliarone AC, Sforcin JM. The effects of propolis and its isolated compounds on cytokine production by murine macrophages. Phytother Res. 2012;26(9):1308-1313. doi: 10.1002/ptr.3731 pmid: 22275284

176. Adeleye IA, Opiah L. Antimicrobial activity of extracts of local cough mixtures on upper respiratory tract bacterial pathogens. West Indian Med J. 2003;52(3):188-190. pmid: 14649097

177. Sayed SM, Abou El-Ella GA, Wahba NM, El Nisr NA, Raddad K, Abd El Rahman MF, et al. Immune defense of rats immunized with fennel honey, propolis, and bee venom against induced staphylococcal infection. J Med Food. 2009;12(3):569-575. doi: 10.1089/jmf.2008.0171 pmid: 19627205

178. Paul IM. Therapeutic options for acute cough due to upper respiratory infections in children. Lung. 2012;190(1):41-44. doi: 10.1007/s00408-011-9319-y pmid: 21892785

179. Moyad MA. Conventional and alternative medical advice for cold and flu prevention: what should be recommended and what should be avoided? Urol Nurs. 2009;29(6):455-458. pmid: 20088240

180. Oduwole O, Udoh EE, Oyo-Ita A, Meremikwu MM. Honey for acute cough in children. Cochrane Database Syst Rev. 2018;4(4):CD007094. doi: 10.1002/14651858.CD007094.pub5 pmid: 29633783

181. Cohen HA, Rozen J, Kristal H, Laks Y, Berkovitch M, Uziel Y, et al. Effect of honey on nocturnal cough and sleep quality: a double-blind, randomized, placebo-controlled study. Pediatrics. 2012;130(3):465-471. doi: 10.1542/peds.2011-3075 pmid: 22869830

182. Dealleaume L, Tweed B, Neher JO. Do OTC remedies relieve cough in acute URIs? J Fam Pract. 2009;58(10):559a-c. pmid: 19874728

183. Kiremidjian-Schumacher L, Stotzky G. Selenium and immune responses. Environ Res. 1987;42(2):277-303. doi: 10.1016/s0013-9351(87)80194-9 pmid: 3552651

184. Hoffmann PR, Berry MJ. The influence of selenium on immune responses. Mol Nutr Food Res. 2008;52(11):1273-1280. doi: 10.1002/mnfr.200700330 pmid: 18384097

185. Burt S. Essential oils: their antibacterial properties and potential applications in foods--a review. Int J Food Microbiol. 2004;94(3):223-253. doi: 10.1016/j.ijfoodmicro.2004.03.022 pmid: 15246235

186. Rodrigues A, Sandstrom A, Ca T, Steinsland H, Jensen H, Aaby P. Protection from cholera by adding lime juice to food - results from community and laboratory studies in Guinea-Bissau, West Africa. Trop Med Int Health. 2000;5(6):418-422. doi: 10.1046/j.1365-3156.2000.00575.x pmid: 10929141

187. Calabrese V, Randazzo SD, Catalano C, Rizza V. Biochemical studies on a novel antioxidant from lemon oil and its biotechnological application in cosmetic dermatology. Drugs Exp Clin Res. 1999;25(5):219-225. pmid: 10568210

188. Gonzalez-Molina E, Dominguez-Perles R, Moreno DA, Garcia-Viguera C. Natural bioactive compounds of Citrus limon for food and health. J Pharm Biomed Anal. 2010;51(2):327-345. doi: 10.1016/j.jpba.2009.07.027 pmid: 19748198

189. Sadeghian M, Azadbakht L, Khalili N, Mortazavi M, Esmaillzadeh A. Oral Magnesium Supplementation Improved Lipid Profile but Increased Insulin Resistance in Patients with Diabetic Nephropathy: a Double-Blind Randomized Controlled Clinical Trial. Biol Trace Elem Res. 2020;193(1):23-35. doi: 10.1007/s12011-019-01687-6 pmid: 30835085

190. Cinar V, Mogulkoc R, Baltaci AK, Polat Y. Adrenocorticotropic hormone and cortisol levels in athletes and sedentary subjects at rest and exhaustion: effects of magnesium supplementation. Biol Trace Elem Res. 2008;121(3):215-220. doi: 10.1007/s12011-007-8052-0 pmid: 17999037

191. Carvil P, Cronin J. Magnesium and implications on muscle function. Strength Condition J. 2010;32(1):48-54. 
192. Laires MJ, Monteiro C. Exercise, magnesium and immune function. Magnes Res. 2008;21(2):9296. pmid: 18705536

193. Guerrero-Romero F, Rodriguez-Moran M. Hypomagnesemia, oxidative stress, inflammation, and metabolic syndrome. Diabetes Metab Res Rev. 2006;22(6):471-476. doi: 10.1002/dmrr.644 pmid: 16598698

194. Mooren FC, Golf SW, Volker K. Effect of magnesium on granulocyte function and on the exercise induced inflammatory response. Magnes Res. 2003;16(1):49-58. pmid: 12735483 